\title{
تقدير الذات وعلاقته بالتنمر لاى المراهقين
}

\section{محما عبدالغني علي عبدالغني*}

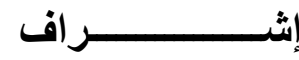

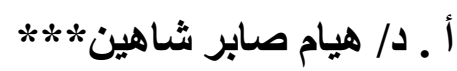

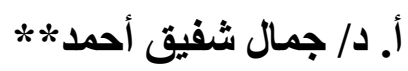

المستخلص

هدفت هذه الدارسة إلى الكثف عن تقدير الذات و علاقته بالتتمر لاى المر اهقين، استخدم الباحث

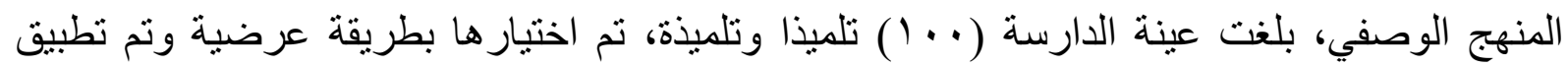
مقياس التنمر إعداد الباحث ومقياس تقدير الذات إعداد "بروس آر هير" (Pruce ,R Hare,1985)

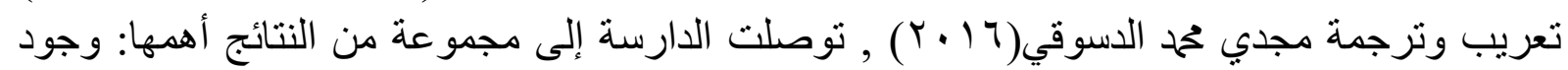

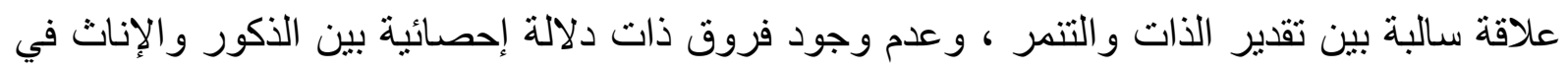

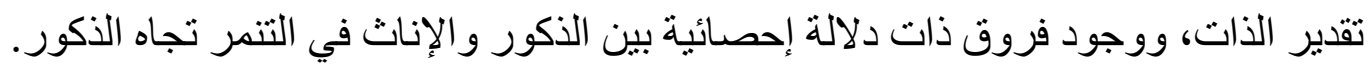
الكلمات المفتاحية : تقدير الذات، التنمر، المر اهقين.

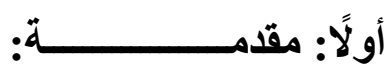

التنمرمن المشكلات الثائعة والخطيرة في الآونة الأخيرة، فهو ظاهرة نعاني منها في بيوتنا

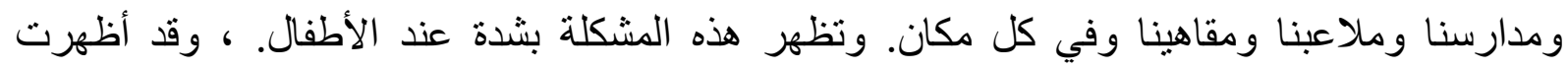

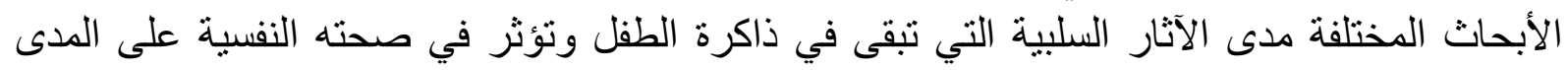

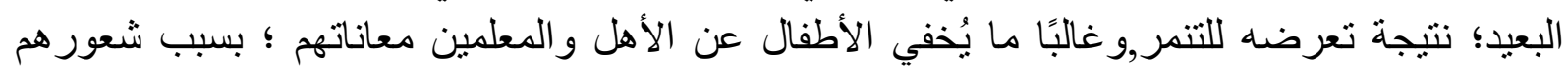
بالخجل؛ لئلا يوصفوا بالضعف، أو رغبة في الحصول على رضا المتنمر، الأمر الذي يحتم علينا

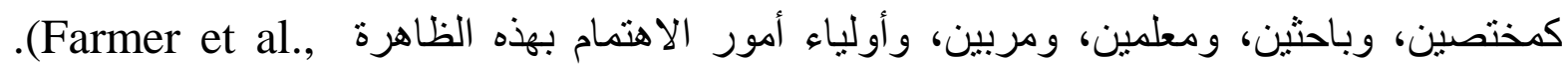

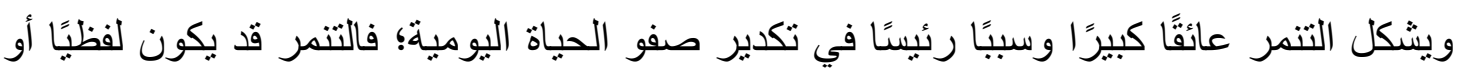

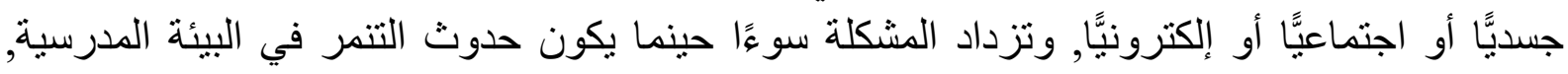

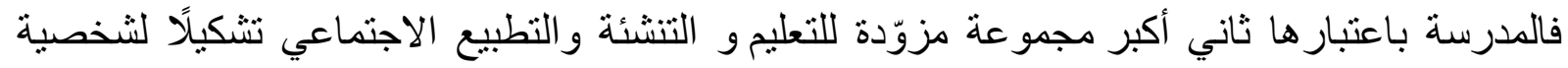
الفرد ، تشهد تفاعلًا لا ينقطع بين أعضائها سواء داخل أسوار المّار المدرسة أو داخل الفصول أو حتى خارجها

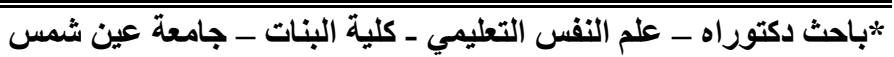

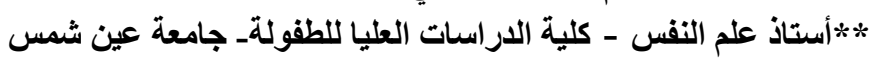

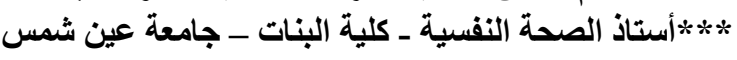
mrmohmed1771984@gmail.com : البريد الاكترتروني 
ـ و غالبًا ما يتضمن هذا التفاعل احتكاكًا بين أفراد المدرسة، و عدوانًا متبادلا أو أحاديًا (طه ربيع عدوي،

ومن الملاحظ أن تقدير الذات يحتل مركزًا مهماً في نظريات الثخصية ، كما يعتبر من العوامل

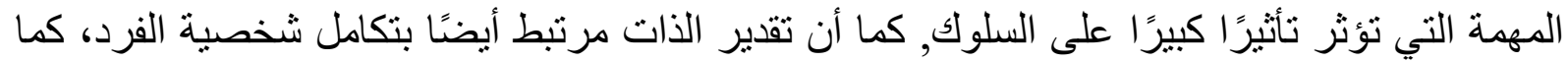

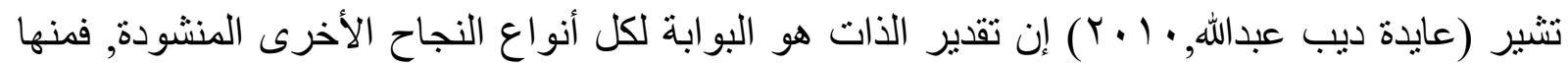

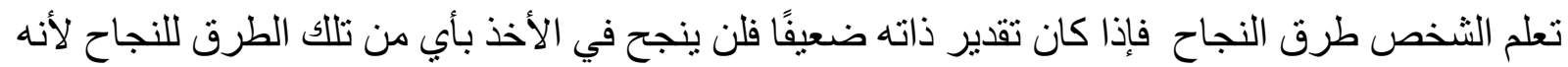

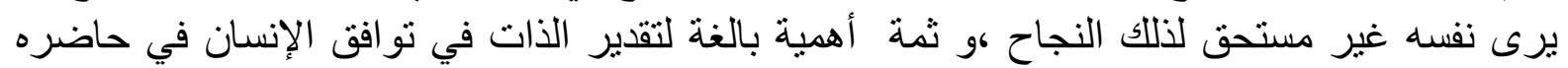

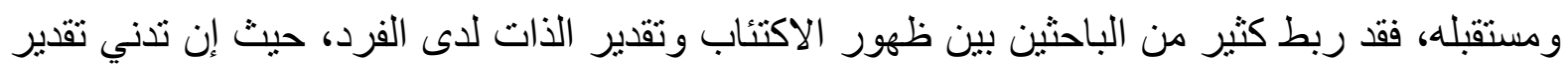

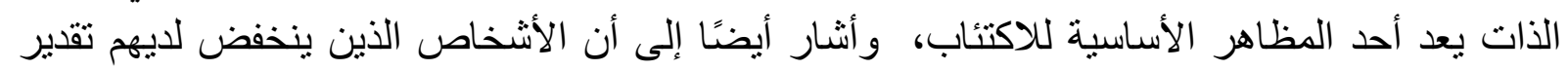

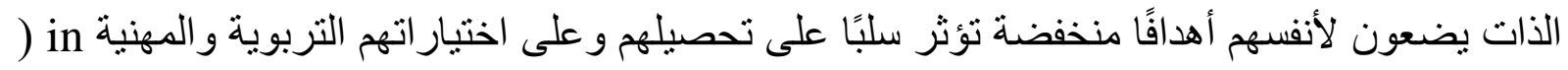

.(Wise and Bandy,1991

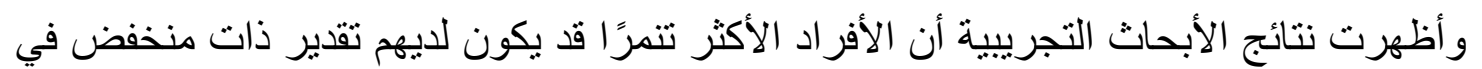

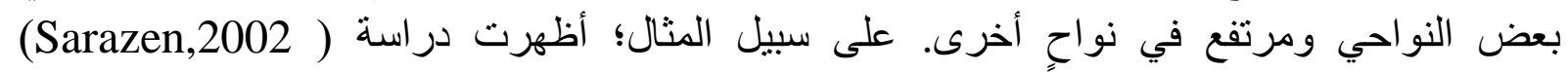

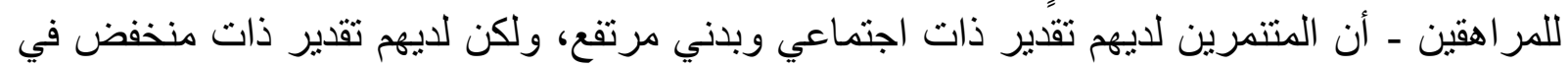

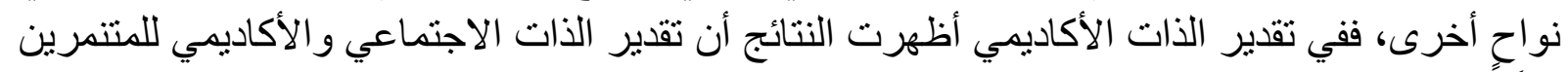

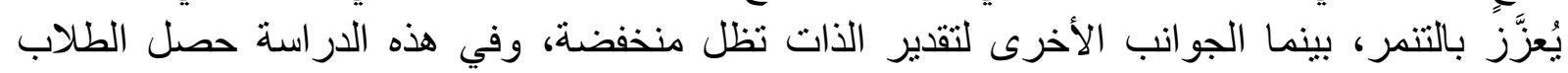

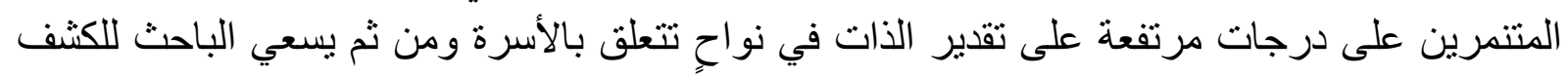
عن ظاهرة التنمر وعلاقتها بتقدير الذات عند تلكَ الفئة.

ثانيًا: مشكلة الدراسة وأسئلتها: - مان

أوضحت الأبحاث أن التتمر الددرسي عبر كل الأعمار والصفوف يرتبط بقضايا الصحة النفسية

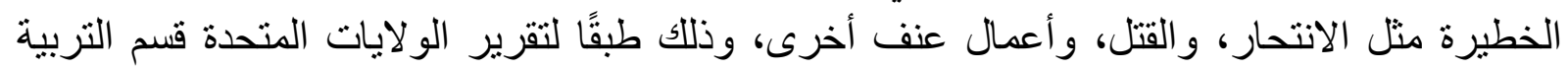

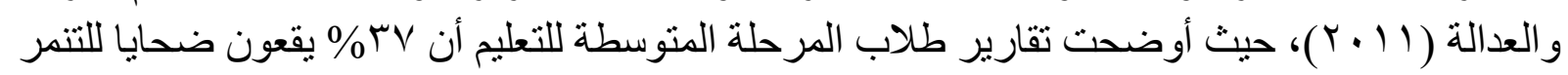

.((Studer \& Mynatt, 2015

ويزداد الاهتمام بدراسة تقدير الذات أيضًا؛ نظرًا للاور الفعال الذي تلعبه شبكات التواصل

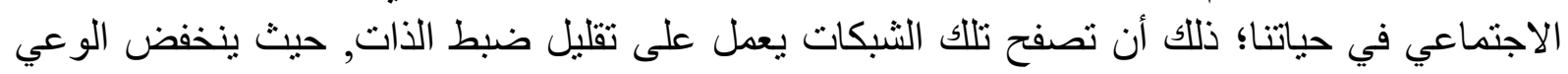

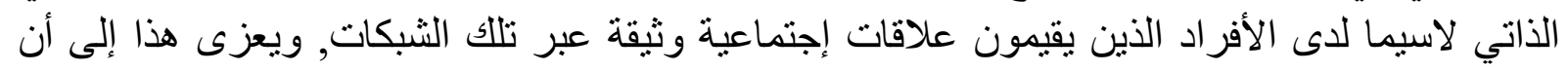

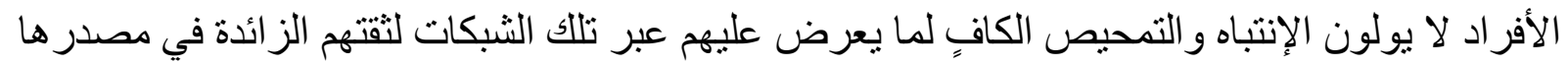

((Wilcox \& Stephen, 2013

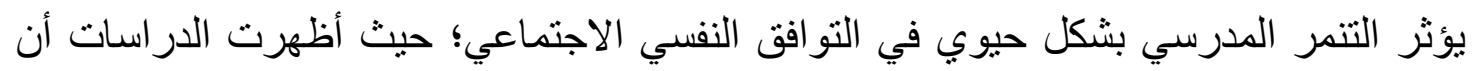

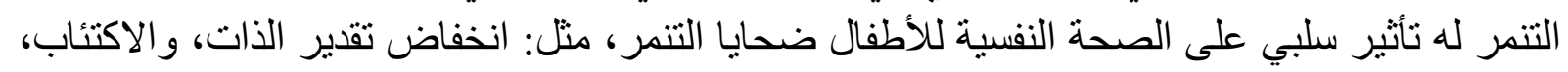
أو ظهور مشكلات سلوكية (Navarro et al., 2015). 
كذلك تثبر الدراسات إلى أن التتمر منبئ بضعف التحصيل الدراسي، واضطرابات الصحة

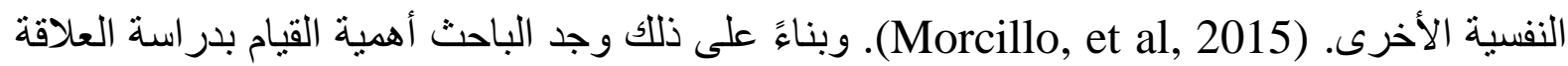
بين تقدير الذات و التنمر لاى المراهقين، وعليه يمكن صياغة مشكلة الدراسة في الأسئلة الآتية:

$$
\begin{aligned}
& \text { 1 ـ ماطبيعة العلاقة الارتباطية بين تقدير الذات و التنمر لدي المراهقين؟ } \\
& \text { r-ما طبيعة الفروق بين الذكور و الاناث في تقدير الذات؟ } \\
& \text { rــ ما طبيعة الفروق بين الذكور و الاناث في التنمر؟ }
\end{aligned}
$$

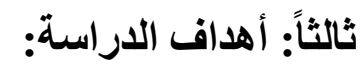

هدفت الدراسة الحالية إلى الكثف عن شكل وقوة العلاقة الارتباطية بين تقدير الذات و التتمر لدى الدى عينة من المر اهقين, و الفروق بين الذكور و الإناث على مقياسى تقدير الذات و التنمر. 1 ـ امكانية تعرف العلاقة بين تقدير الذات والتنمر لدي المر اهقين. r ـامكانية تفسير الفروق بين الذكور و الاناث في تقدير الذات. ץ-امكانية تفسير الفروق بين الذكور و الاناث في التنمر.

$$
\text { رابعاً: أهمية الاراسة أهية الدر اسة فيما يلى : تحدت }
$$

1ـ أهمية المتغير ات: كثفت الدر اسة قبيل الاستطلاعية, ومواقع شبكة الإنترنت عن تعاظم اهتمام

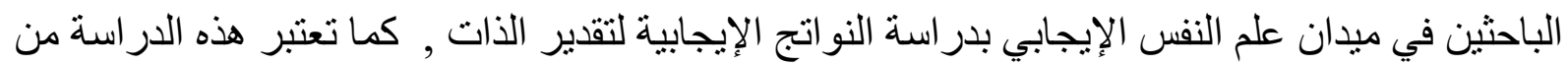

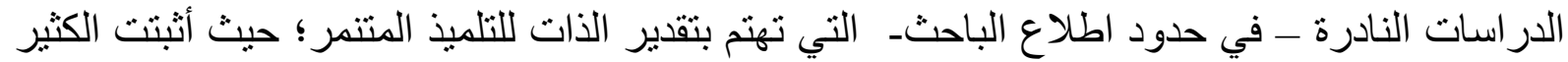
من الدراسات الأجنبية أن التنمر يؤنز على الجو انب النفاحت النفية والاجتماعية والأكاديمية.

r ـ أهمية العينة: تمثل مرحلة المر اهقة فترة مهمة جدَّا وخطيرة في بلورة شخصية الإنسان, حيث يتم فيها زرع وترسيخ المبادئ و القيم و الأيدولوجيات. r - الأهمية السيكوميترية؛ تهنم هذه الدر اسة بتصميم مقياس لتقدير التتمر لدى المر اهقين. خامسًا: مصطلحات الدراسة لمتغيرات الاراسة توتم هذه الدر اسة بتناول المصطلحات الاتية: أولًا: تقدير الذات: Self esteem:-

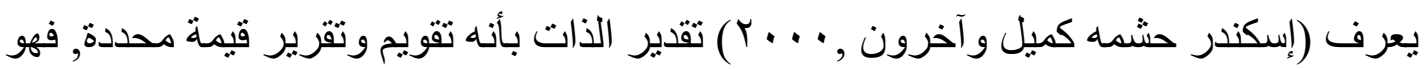

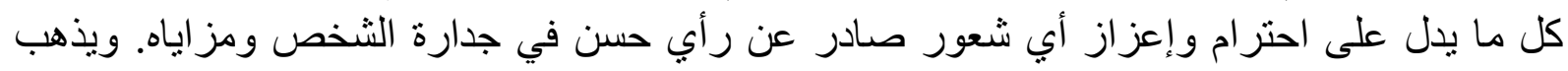
(Martinot,2002) 


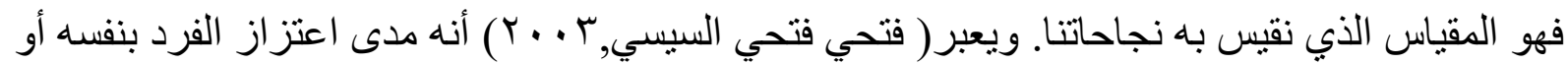

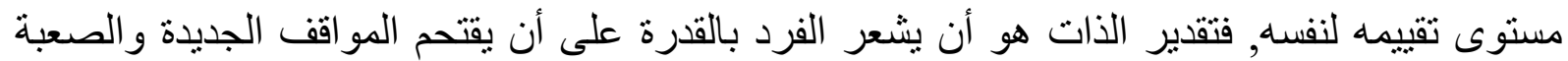

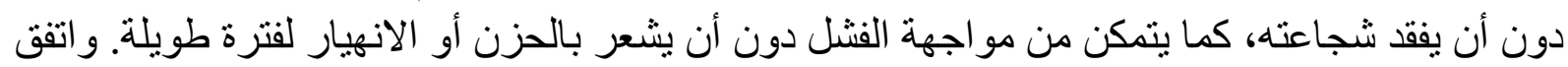

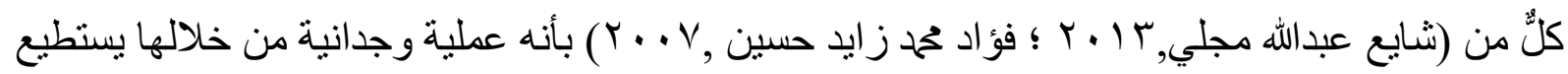

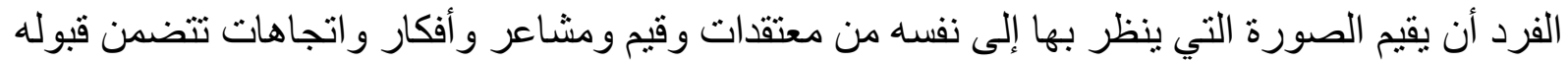

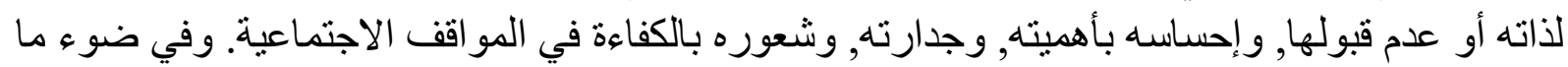

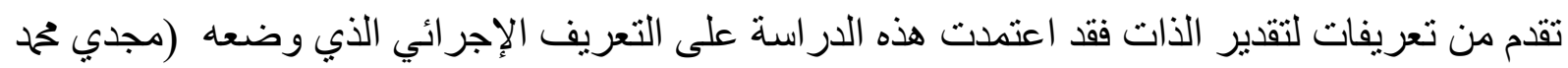

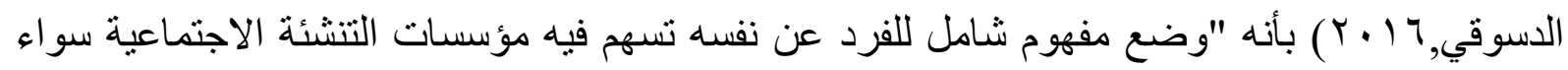

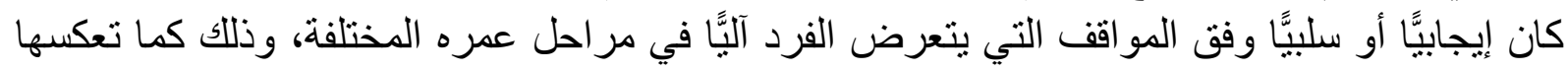

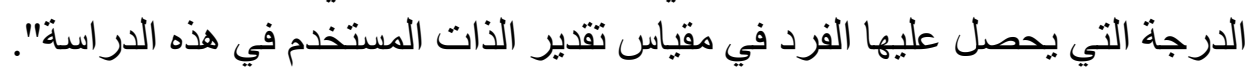

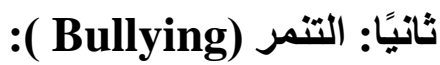

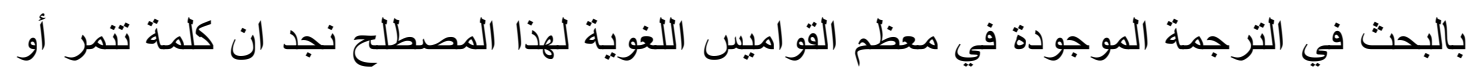

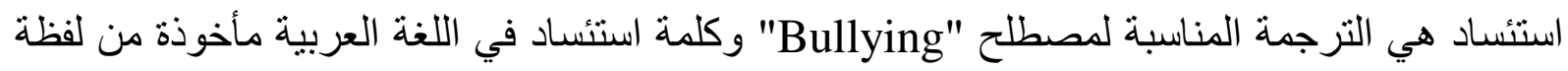

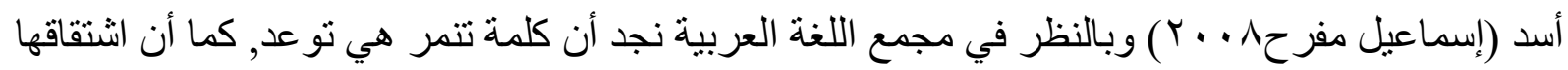

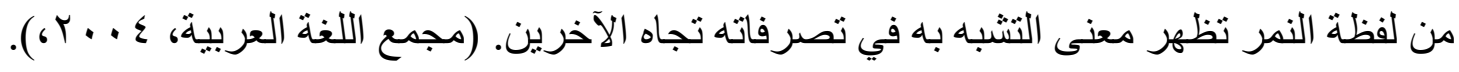

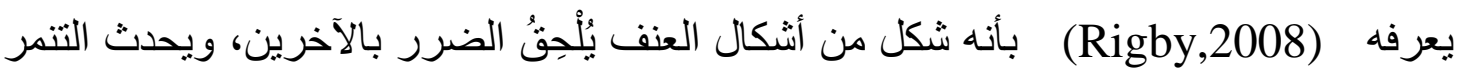

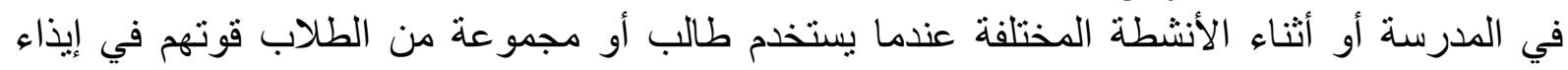

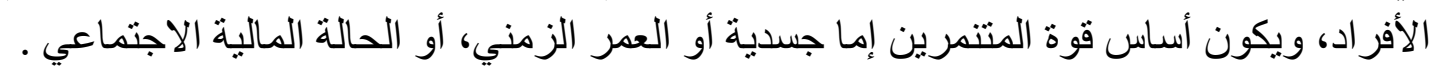

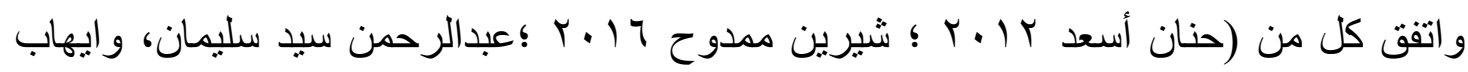

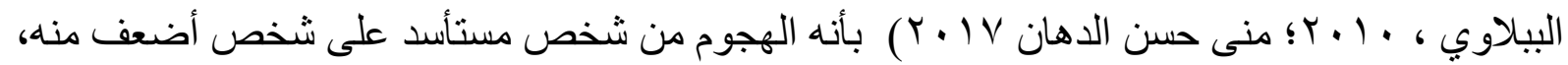

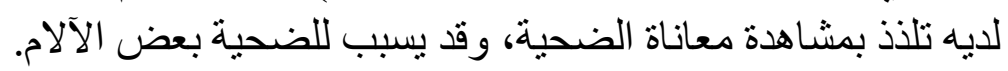

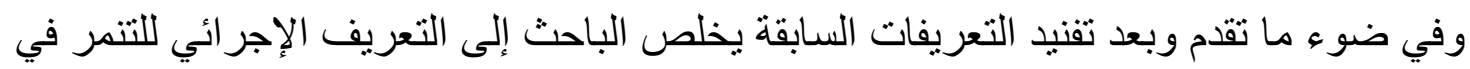

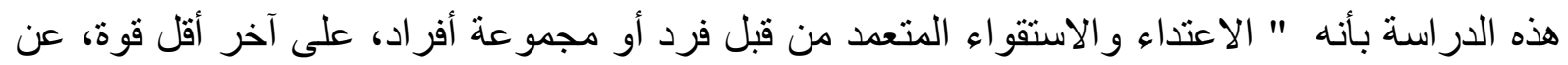

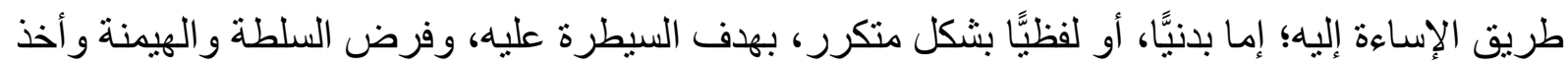

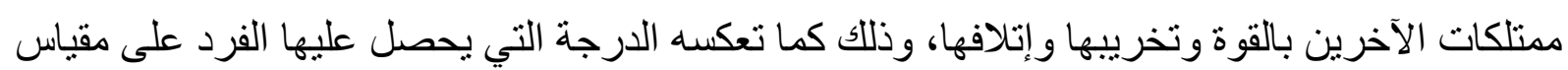
التنمر المعد في هذه الدراسة".

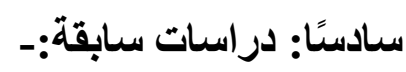
يمكن عرض الدر اسات السابقة المعنية بموضوع هذه الدراسة من خلال المحاور التالية: 
المحور الأول: دراسات اهتمت بتقدير الذات لاى المراهقين:

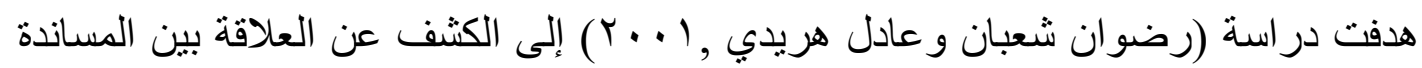

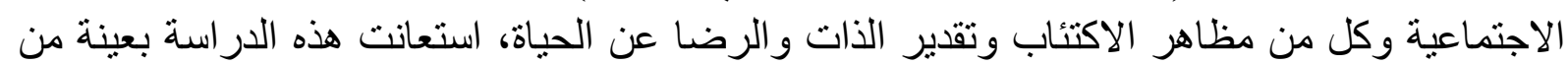
طلاب الثانوية المقيدين للار اسة في إحدى المدارس السعودية , واستخدم الباحث مقياس المساندة الاجتماعية وقائمة بك للاكتئاب ومقياس تقدير الذات، وقد توصلت الدراسة إلي وجود علاقة ارتباطية

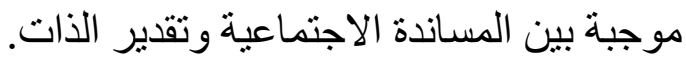

كما هدفت دراسة (روبين فواز أبو جهل ,2003) إلى الكثف عن العلاقة بين القلق وتقدير

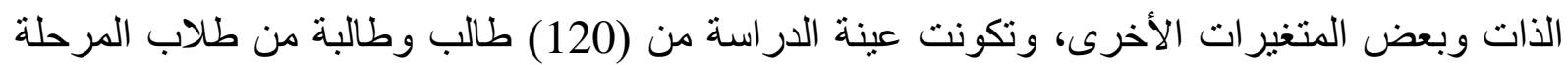

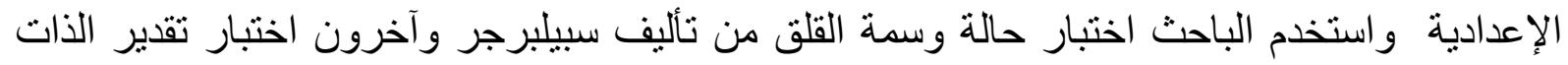
ومن ثم توصلت الدر اسة الي النتائج التالية: وجود علاقة التة وارتباطية سالبة بين مقياس القلق كحالة, ومقياس تقدير الذات, ومع الدرجة الكلية للقلق.

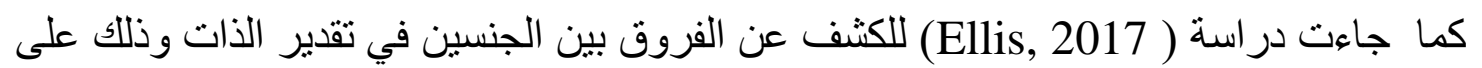

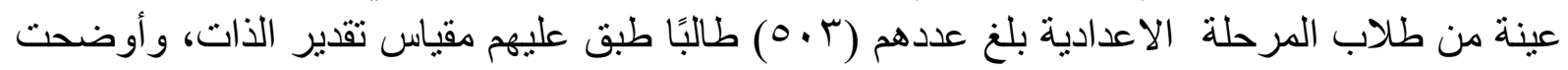

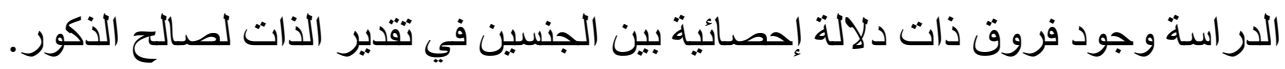

$$
\text { المحور الثاني : در اسات اهتمت بالتنمر لدى المر اهقين: }
$$

اهتمت در اسة (Morcillo et al., 2015) بتناول السياق الثقافي الاجتماعي للتتمر بالآخرين

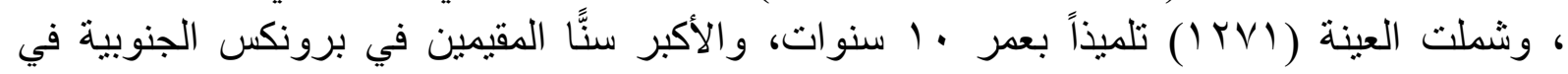

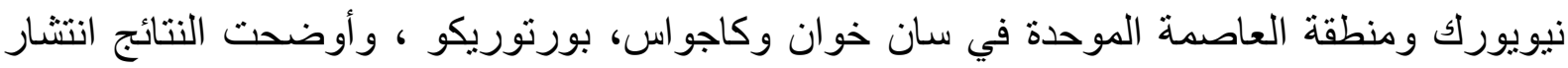

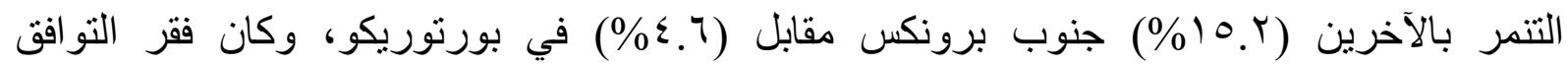

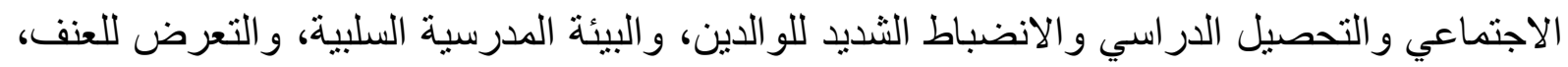
وجنوح الأقران، ومستوى التبادل الثقافي للطفل، جمعهم عو امل خطر للتنمر بالآخرين.

كما قام (Navarro et al, 2015) بتطبيق أربعة مقاييس لهوية الجنس ، ومقياسان لنمط نوع

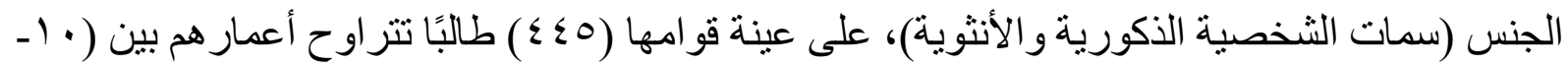

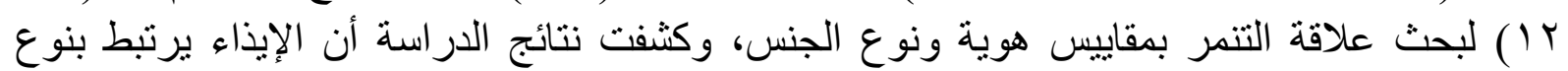

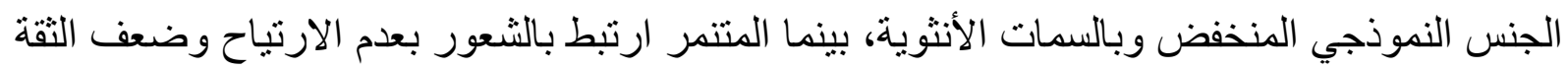

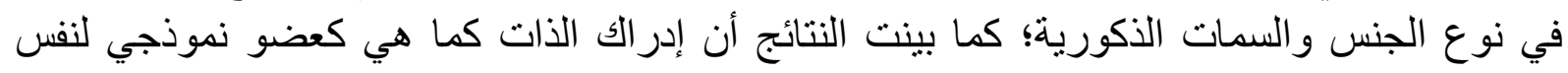

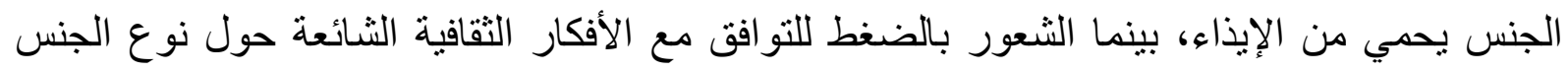
ونقص الرضا عن نوع الجنس من عو امل ارتفاع معدل التنمر.

كما قام (تحمد محمود يونس، 1 ( • ب) بدر اسة الحالات الانفعالية المميزة للطلاب المتنمرين

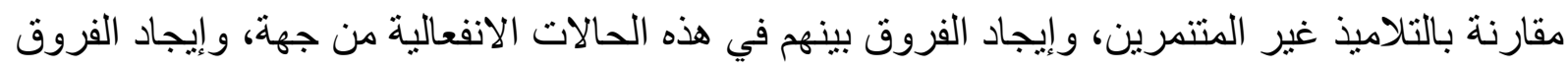
في هذه الحالات تبعًا لبعض المتغير ات الديمو غر افية لدى الطلاب المتنمرين فقط من جهة ثانية، ولتحقيق 
ذللك طبق مقياس الحالات الانفعالية على عينة من الطلاب المتتمرين من الصفوف (السابع و الثامن

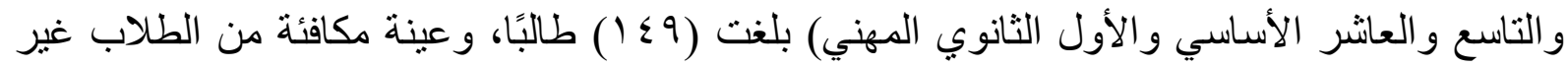

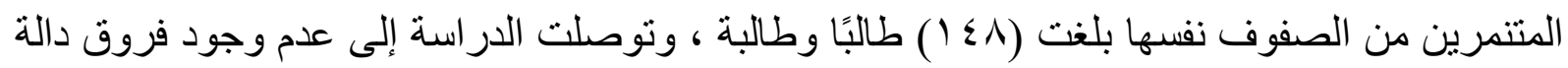

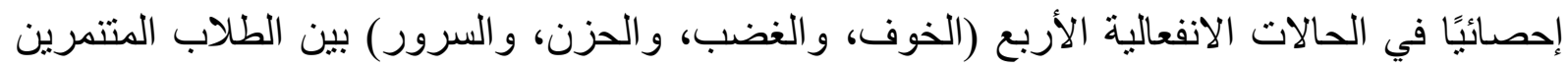

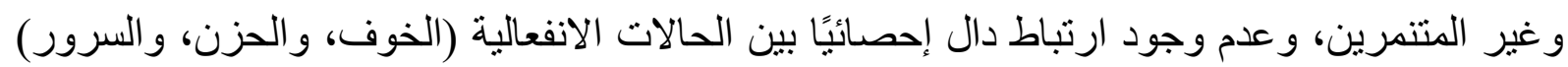

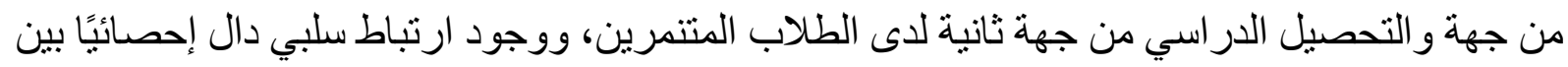

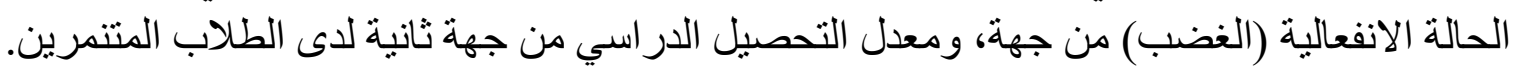

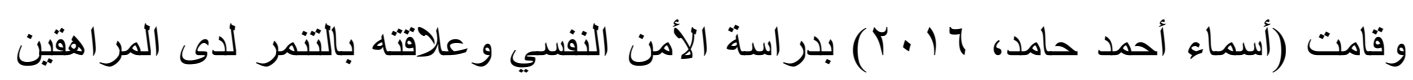

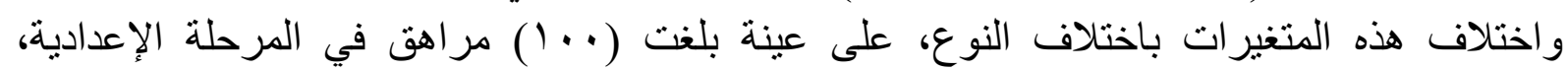

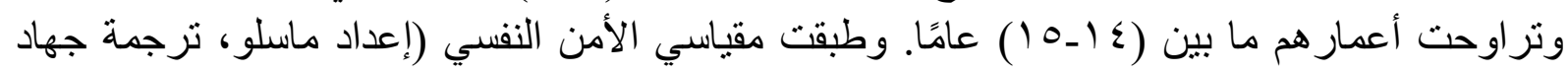

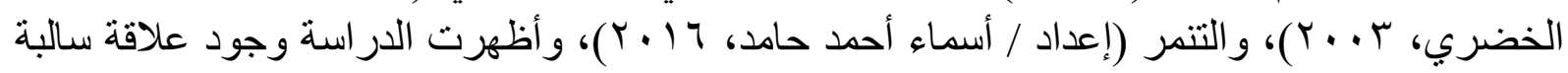

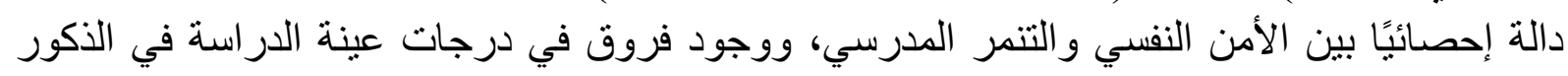
والإناث على مقياس التتمر تجاه الذكور.

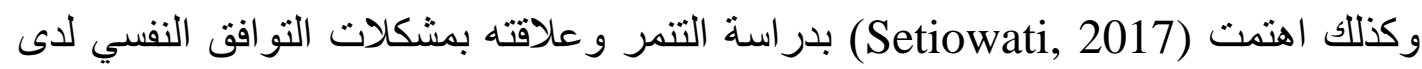

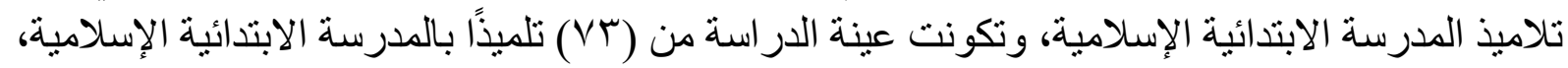

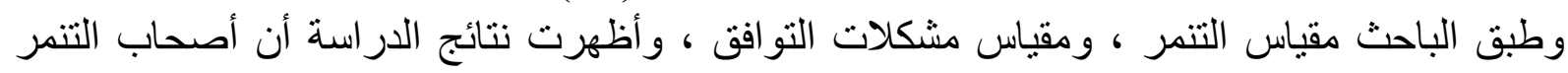

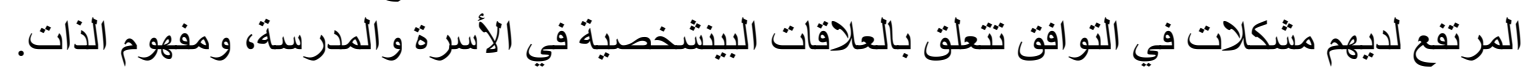

وقامت در اسة (Mustafa Nazia, 2018) بالكثف عن معدل انتشار إيذاء الأقران و علاقته

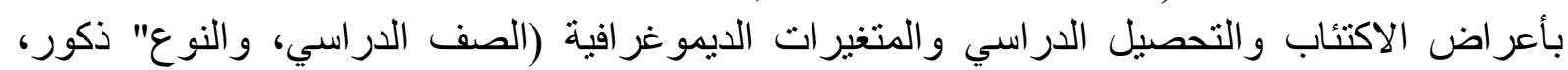

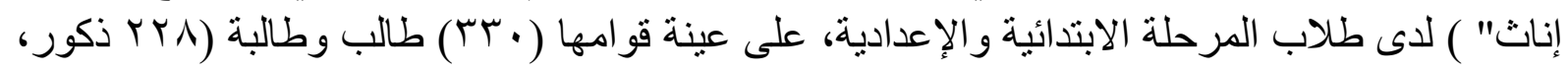

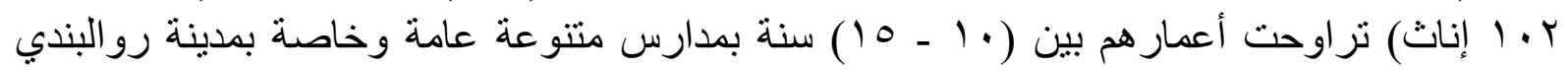

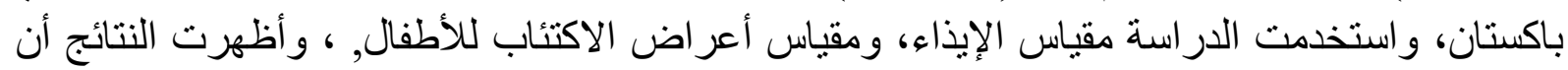

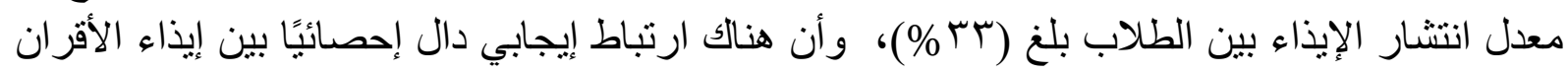

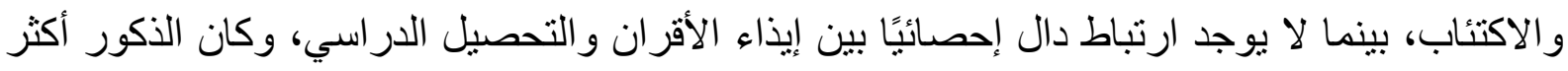
تنمرًا و عرضة للاكتئاب مقارنة بالإناث.

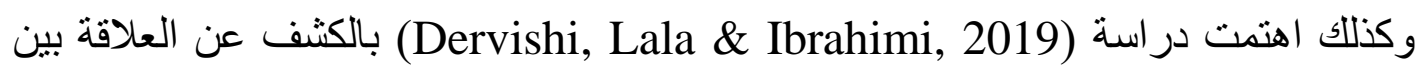

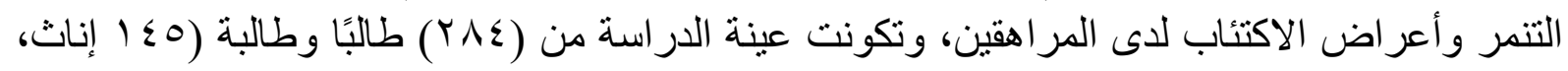

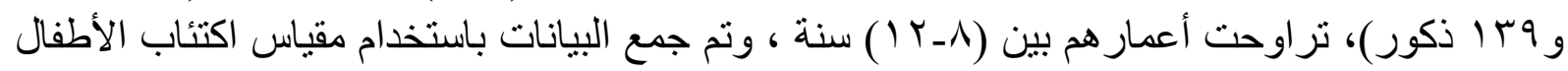

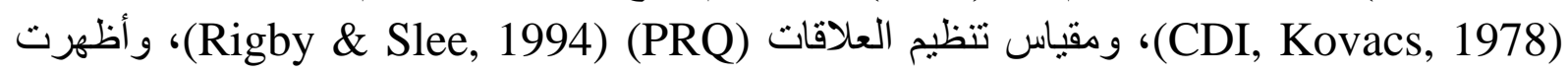

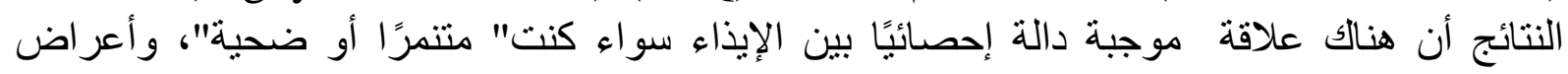

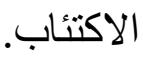


هدفت دراسة (صوفي فطيم زهير, 19 (ب) إلى الكثف عن العلاقة بين المناخ المدرسي

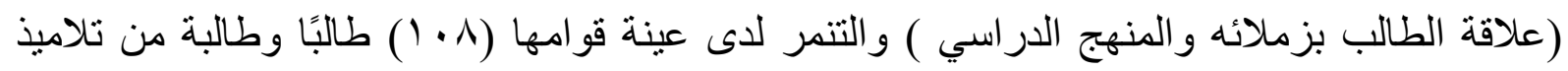
المرحلة الابتدائية بالصف الر ابع والخامس تتر اوح أعمار هم من (9 ـ (1 ) سنة , و وتم تطبيق مقياس التنمر على الطلاب بأربعة أبعاد (التنمر اللفظي والجسدي والاجتماعي والاستيلاء على الممتلكات و أسفرت النتائج إلى عدم وجود فروق ذات دلالة إحصائية في سلوك التنمر تعزى لكل من متغير الجنس و المستوى الاجتماعي, ووجود علاقة ارتباطية موجبة بين المناخ المدرسي والتنمر تجاه المتنمرين.

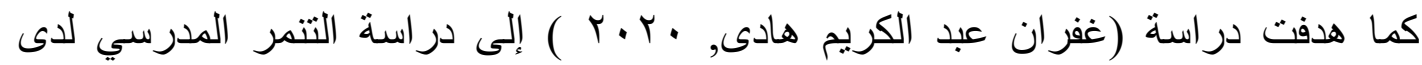

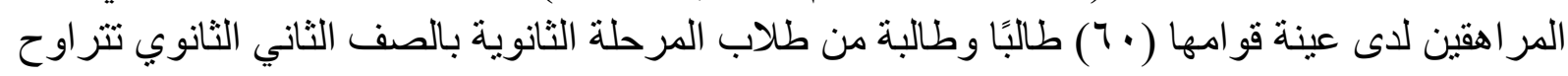
أعمار هم من أن أنمن

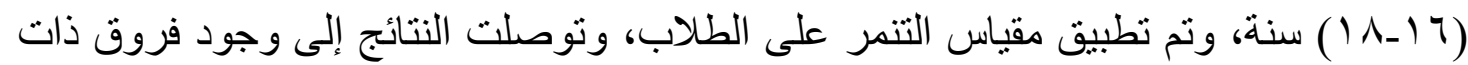

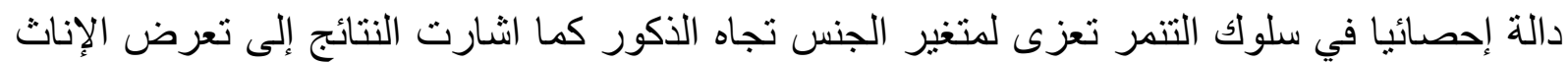
للتنمر أكثر من الذكور.

المحور الثالث: دراسات اهتمت بالعلاقة بين تقدير الأات والتنمر لاى المراهقين:

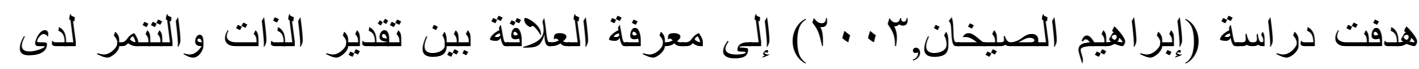

طلاب المرحلة المتوسطة، نكونت عينة الدر استة من (798) طالب وطالبة من المرحلة المتوسطة, استخدم الباحث مقياس تقدير الذات إعداد بروس آر هير( R Hare,Pruce, 1985 ) ومقياس السلوك التنمري، وقد أسفرت هذه الدر اسة عن وجود علاقة ارتباطية سالبة دالة إحصائيا بين مستويات تقدير الذات (العائلي

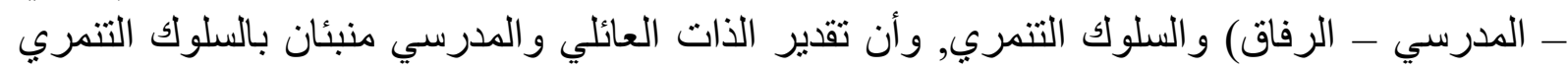
و تقدير الذات العائلي أكثر إسهاما في التنبؤ بالسلوك التنمري من تقدير الذات المدرسي, كما بينت أنه لا لاني يوجد فروق ذات دلالة إحصائية في السلوك التنمري باختلاف التئي التقدير الدر اسي.

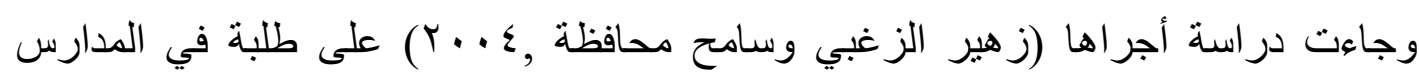

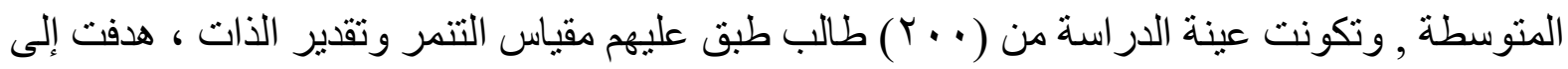
معرفة أثر بعض المتغيرات في الاتجاه نحو السلوك التنمري ، و أثنكال السلوك التنمري السائد لديهم، وقد

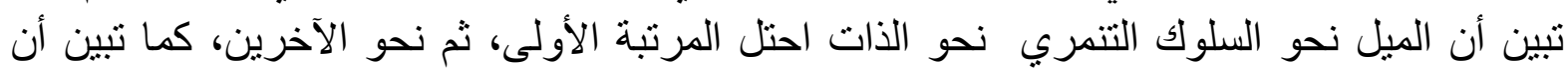

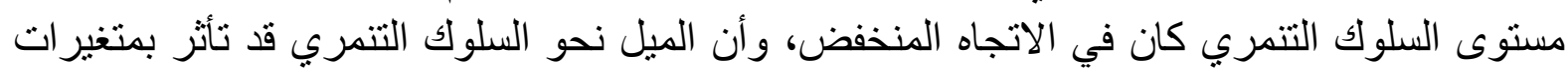
الجنس و عدد أفر اد الأسرة الترئ كان

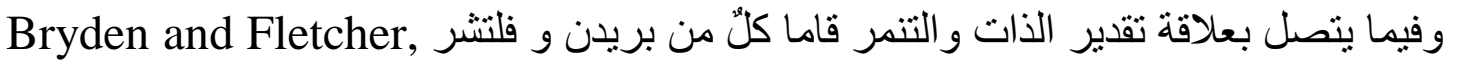

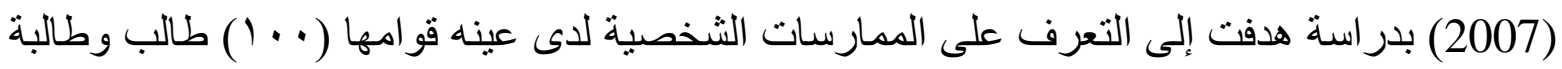

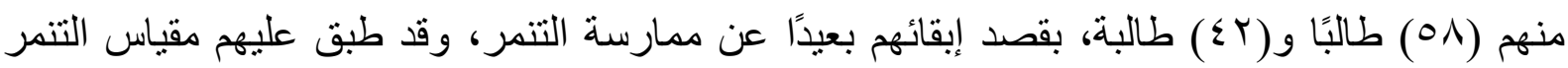

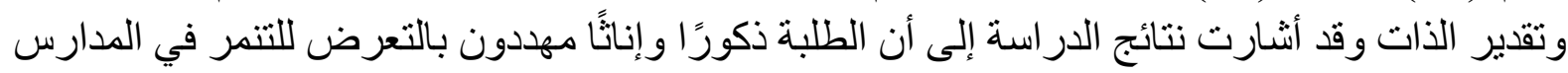

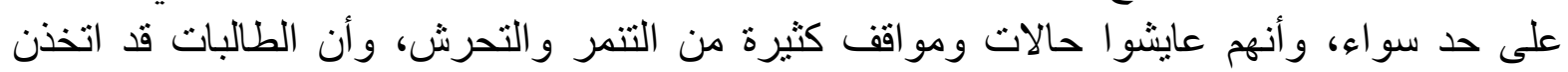


إجر اءات أمنية أكثر، مما اتخذه الطلبة الذكور، كما أثنارت النتائج إلى وجود ارتباط سالب بين ارتفاع

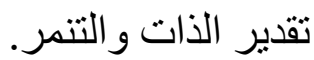

و هدفت دراسة (ناجي عبدالعظيم سعيد , ... ب)، إلى التعرف على على علاقة تقدير الذات بالسلوك

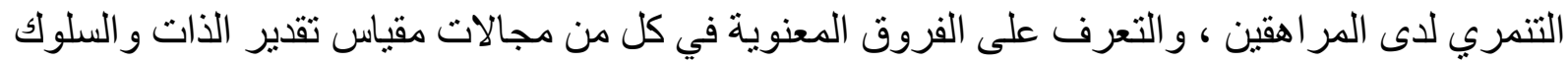

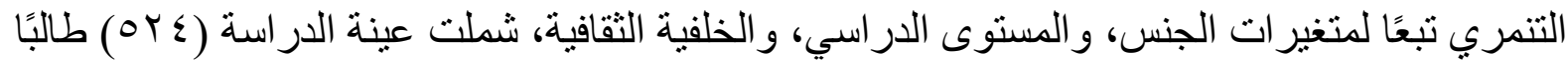

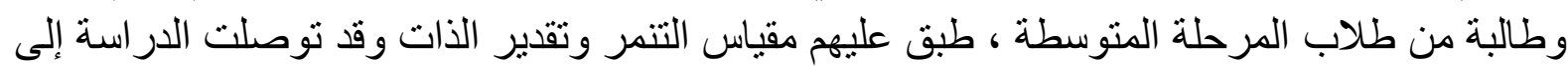

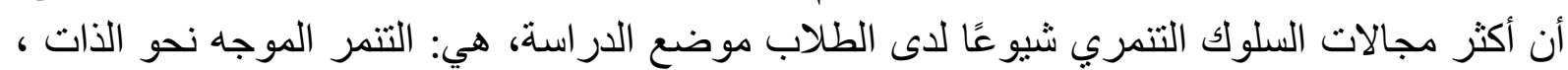

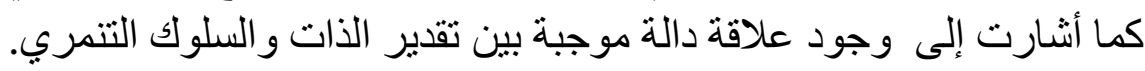

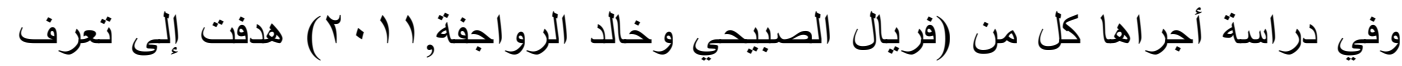

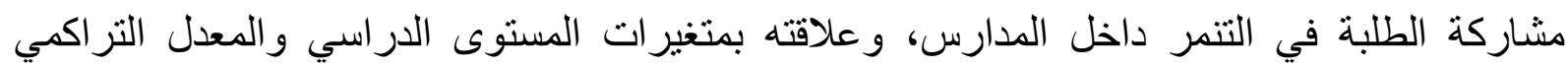

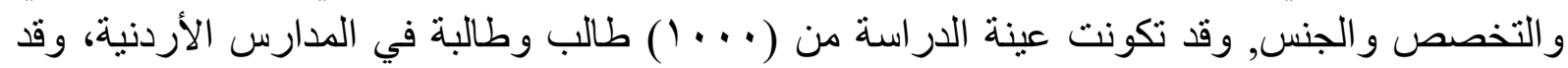

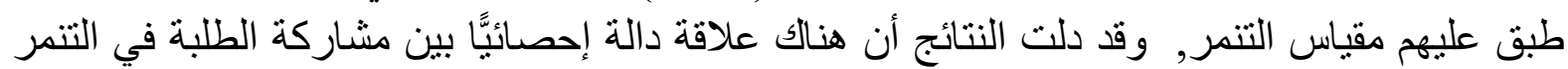

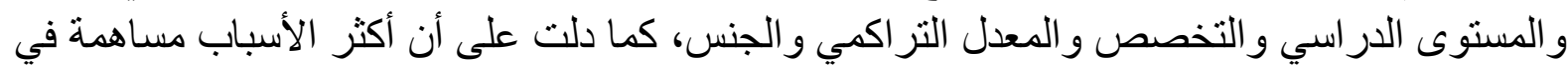

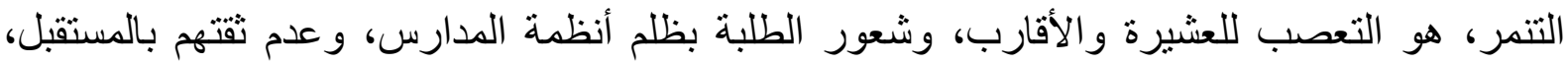

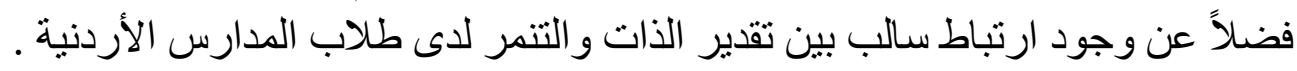

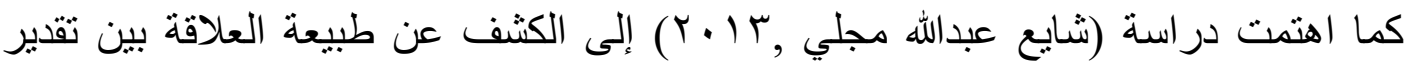

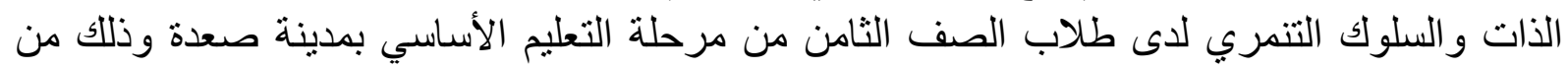

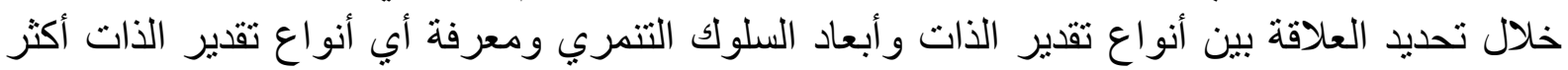

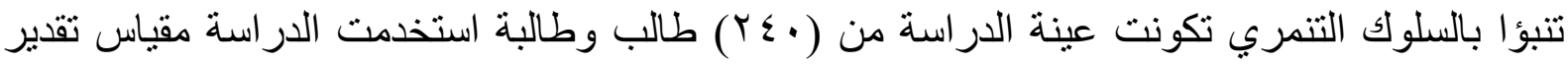

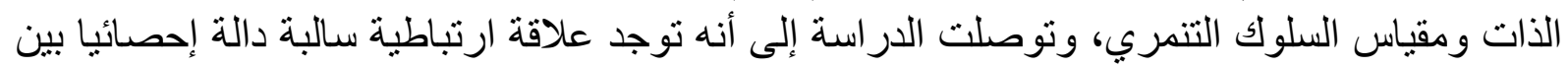

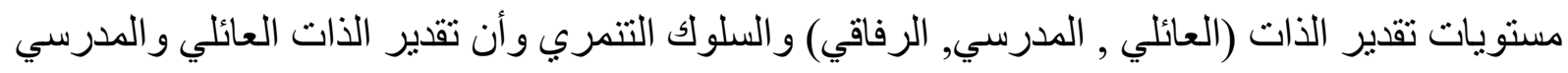

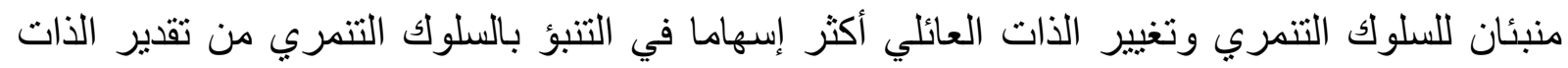

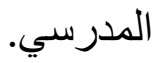

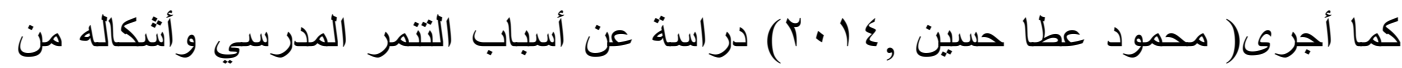

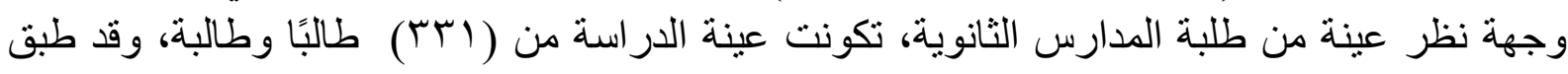

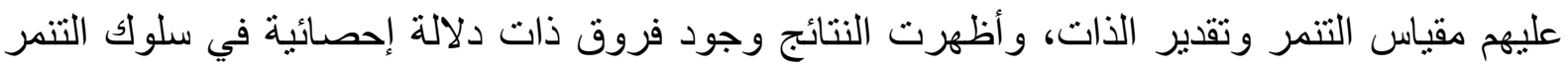

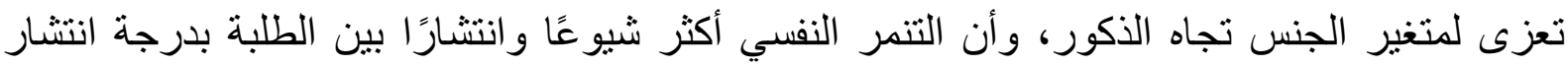

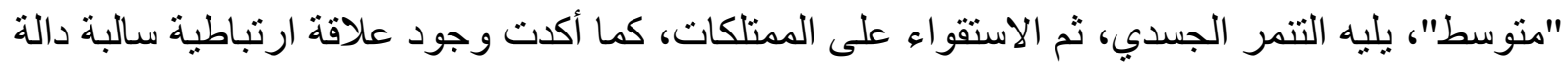
إحصائيا بين تقدير الذات و السلوك التنمرى.

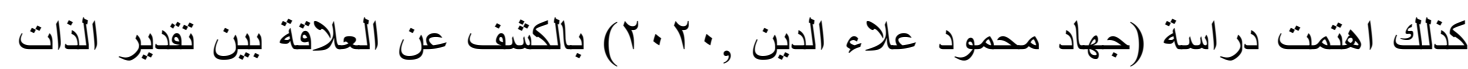

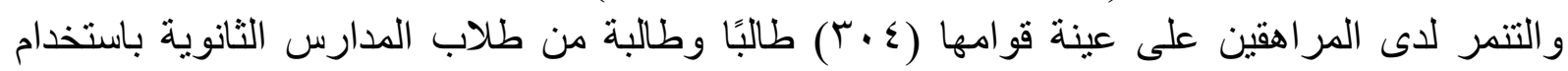

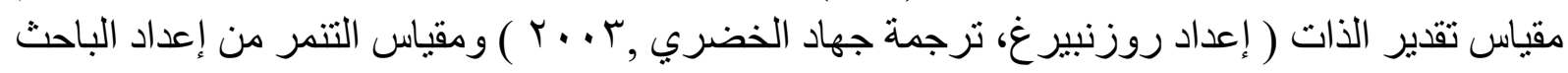


و أسفرت النتائج, عن وجود علاقة سالبة دالة إحصائيا بين تقدير الذات والتنمر ووجود فروق في درجات عينة الدراسة في الذكور و الإناث على مقياس التنمر تجاه الذكور.

$$
\text { تعقيب على الدراسات السابقة: }
$$

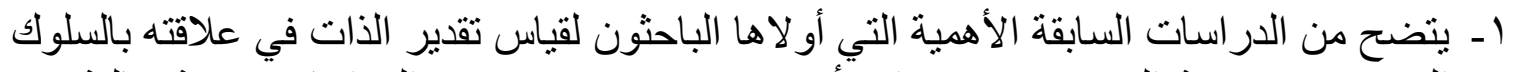

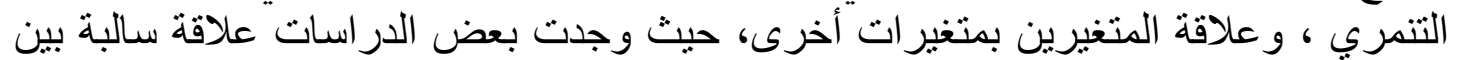

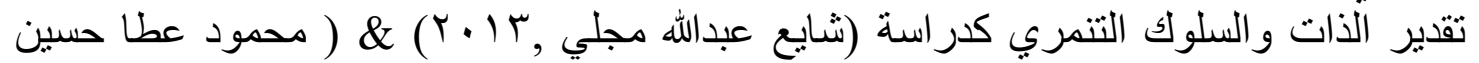
.( (Y.) $\varepsilon$,

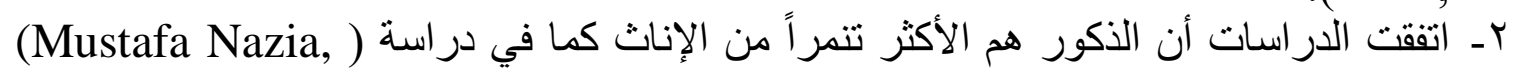

.(Dervishi, Lala \& Ibrahimi, 2019) \& 2018 rـ أثنارت الدراسات إلى أهمية تقدير الذات لخفض التنمر لدى المتنمرين المراهقين كدراسة

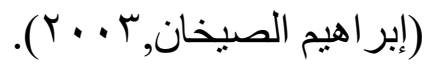

$$
\text { سابعًا: فروض الدراسة }
$$

ا ـ توجد علاقة ارتباطية دالة إحصائية بين درجات عينة الدراسة علي مقياسي تقدير الذات

$$
\text { و التنمر. }
$$

r-لا توجد فروق دالة احصائيا بين درجات مجموعة الذكور ومجموعة الاناث علي مقياس

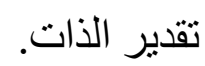

عـ لا توجد فروق دالة احصائيا بين درجات مجموعة الذكور ومجموعة الاناث علي مقياس التنمر.

$$
\text { ثنامنًا: منهج وإجراءات الاراسة }
$$

تم اتباع المنهج الوصفي الارتباطي لبحث العلاقة بين المتغيرين ( تقدير الذات ، و والتنمر لأى المر اهقين)

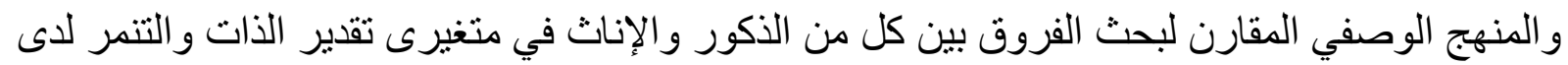

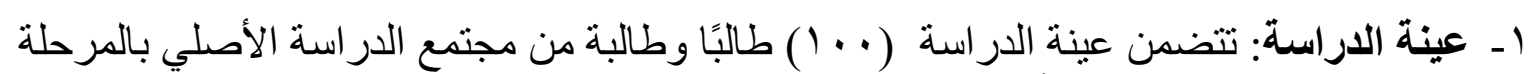

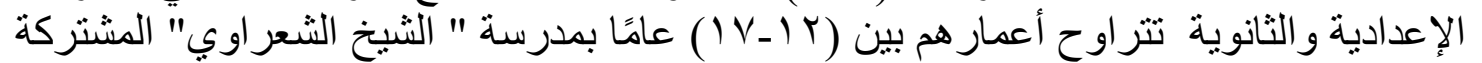

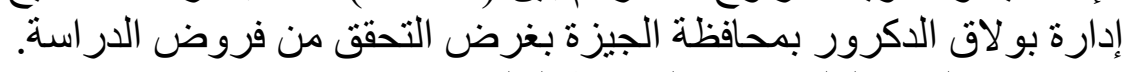

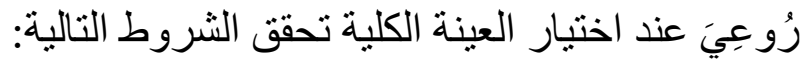

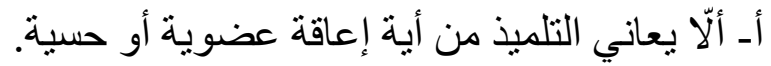

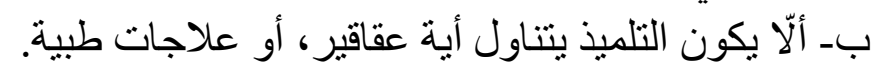

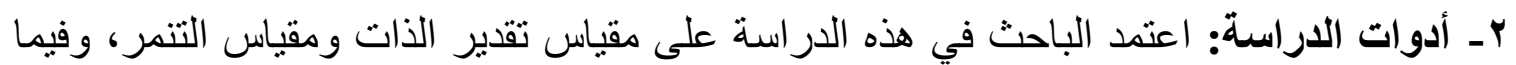

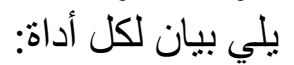
أولاً: مقياس تقدير الذات إعداد "بروس آر هير" (Pruce ,R Hare1985) تعريب وترجمة مجدي محمه الاسوقي الهذف من المقياس: يهدف هذا المقياس إلى تقدير درجة تقدير الذات لدى المر اهقين . 


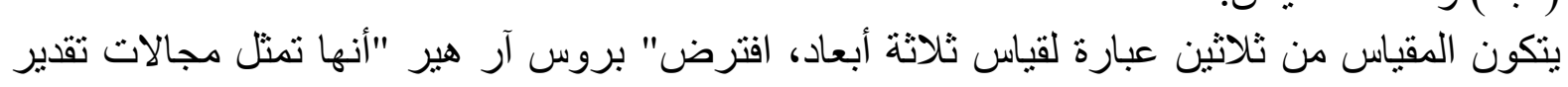

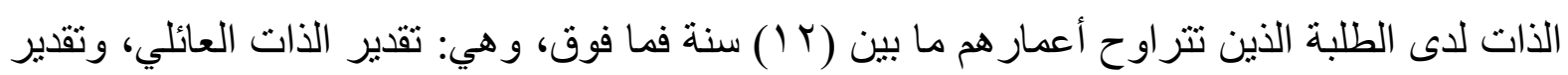

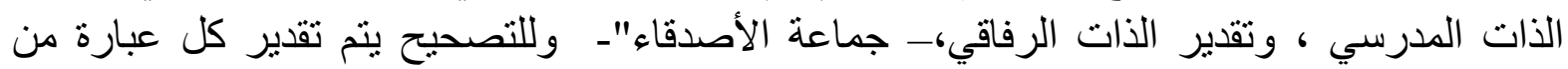

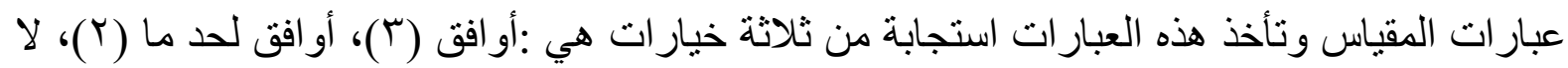

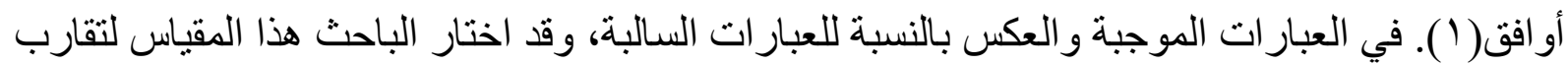

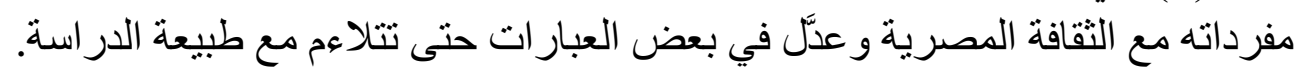

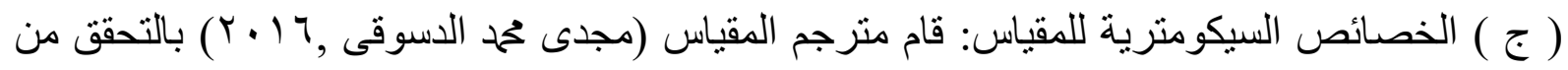
صدق وثبات المقياس على النحو التالي :

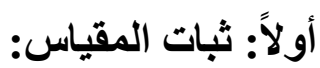
لحساب ثبات المقياس تم حساب الثبات عن طريق التجزئة النصفية لسبيرمان بحساب الأعداد الفردية

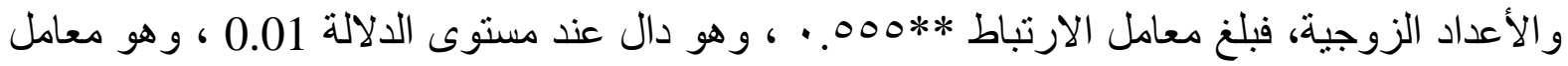

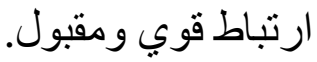

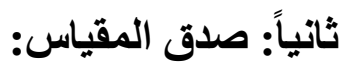
للتأكد من صدق المقياس تم استخدام أربعة مؤشرات، وهي المدي على النحو الآتي:

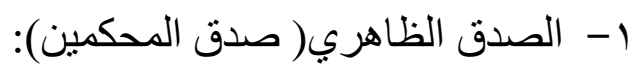

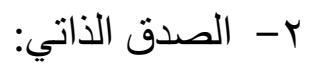

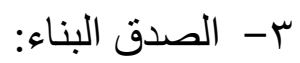
ع - الصدق المقارنة الطرفية ( الصدق التمييزي)

ثالثاً: طريقة الاتساق الاخلي

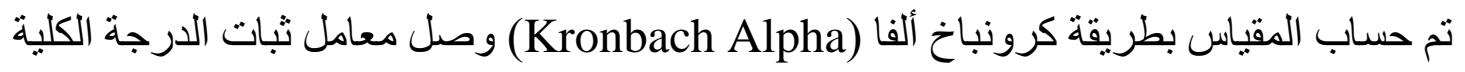
0.790 , ويتضح من ذلك أن المقياس له درجتا صدق وثبات تؤيدان استخدامه في مجتمع البحث

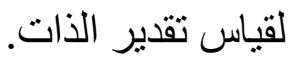

ثانيا: مقياس التنمر (من إعداد الباحث):

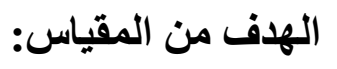
يهدف هذا المقياس إلى تقدير درجة التنمر لايى المر اهقين . (ب) وصف المقياس: يتكون هذا المقياس في صورته النهائية من (9 (1) عبارة تقيس سلوك التنمر لدى المراهقين في الأبعاد التالية: 


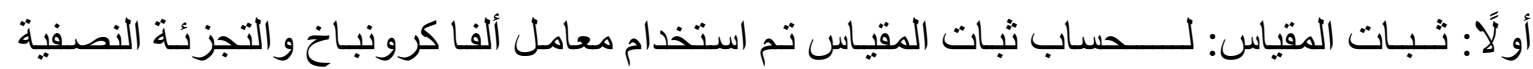

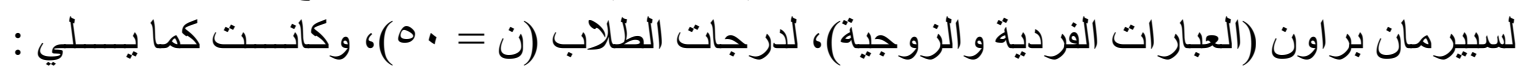

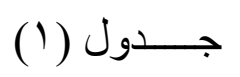

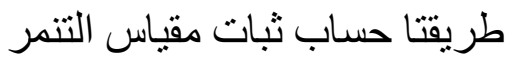

\begin{tabular}{|c|c|c|}
\hline معامل الثبات & طرق حساب الثبات & r \\
\hline$\cdot, T \leqslant \mu$ & 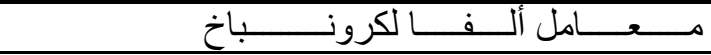 & 1 \\
\hline$\cdot, 7 \leqslant 1$ & 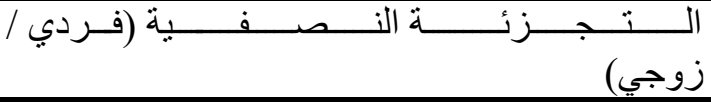 & $r$ \\
\hline
\end{tabular}

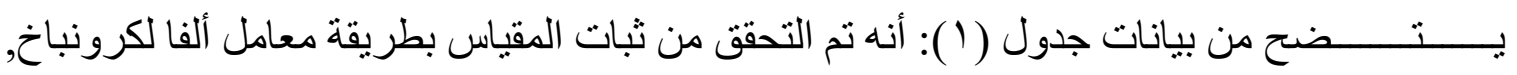

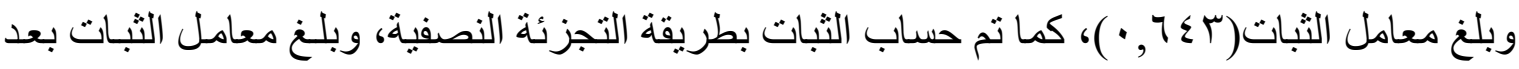

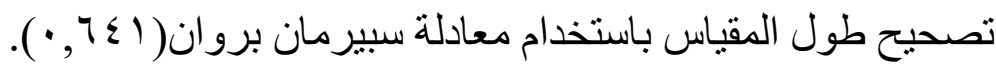
ثنانيًا صدق المقياس: تم حساب صدق المقياس بطريقتين كما يلي: -

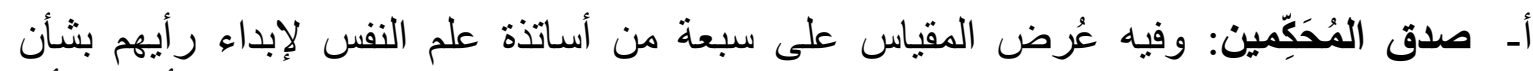

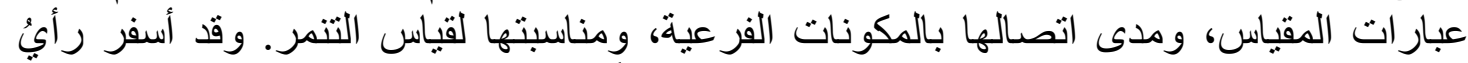

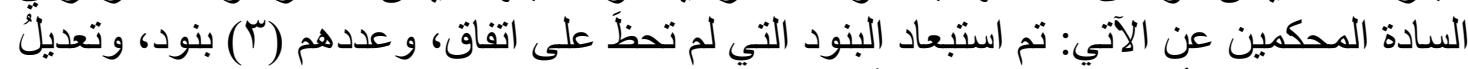
بعض البنود و إعادةُ صياغتها، وبالتالي أصبح المقياس في صورته النهائية يتكون من (9 (1 ) بندًا .

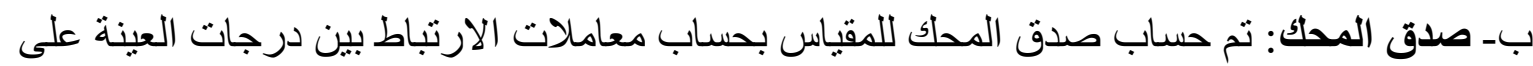

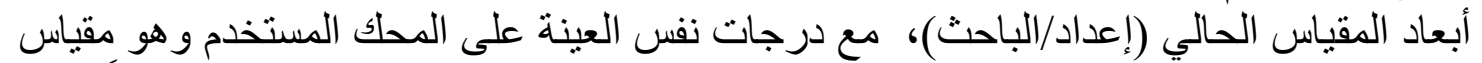

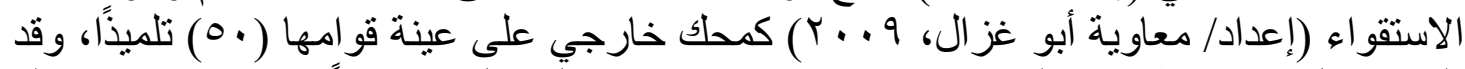

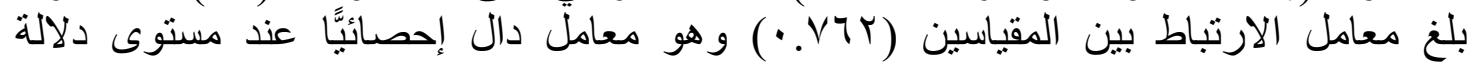

$$
(\cdot \cdot 1)
$$

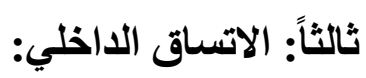

تم التحقق من الاتساق الداخلي للمقياس عن طريق حساب معامل الارتباط بين درجات أفراد العينة على كل عبارة و الدرجة الكلية للبعد الذي تلتمي إليه. 
جدول (r) (ب)

معاملات الاتساق الداخلي بين كل مفردة و الدرجة الكلية للبعد الذي تتنمي إليه (ن = • )

\begin{tabular}{|c|c|c|c|c|c|}
\hline \multicolumn{2}{|c|}{ الاستقو اء على الممنلكات } & \multicolumn{2}{|c|}{ التنمر اللفظي } & \multicolumn{2}{|c|}{ التنمر البدني } \\
\hline معامل الارتباط & العبارة & الارتباط & العبارة & معامل الارتباط & رقم العبارة \\
\hline $.433 * *$ & r & 0.389 & r & $0.317 *$ & 1 \\
\hline $.546 * *$ & 7 & $.438 * *$ & 0 & 0.580 & $\varepsilon$ \\
\hline $.654 * *$ & 9 & $.486 * *$ & $\Lambda$ & $.601 * *$ & V \\
\hline $.458 * *$ & IT & 0.538 & 11 & $.517 * *$ & 1. \\
\hline $.576 * *$ & 10 & $.598 * *$ & $1 \varepsilon$ & $.576 * *$ & $\pi$ \\
\hline & & $.553 * *$ & 11 & $.568 * *$ & 17 \\
\hline & & $.583^{* *}$ & 19 & & \\
\hline
\end{tabular}

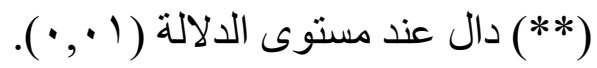

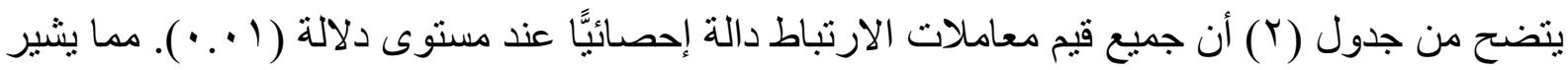
إلى الاتساق الداخلي المرتفع لمفردات مقياس التنمر.

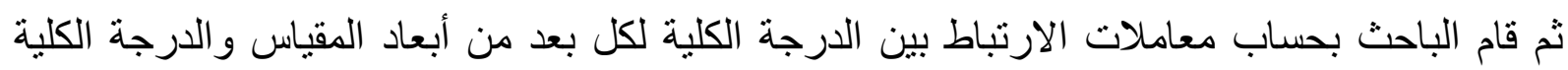

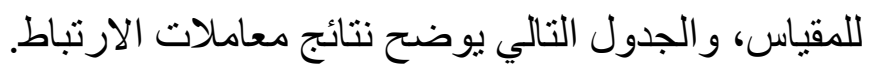

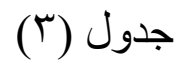

معاملات الاتساق الداخلي لأبعاد مقياس التنمر مع الدرجة الكلية للدقياس (ن = •0)

\begin{tabular}{|c|c|}
\hline معاملات الارتباط & الأبعــــاد \\
\hline $.829 * *$ & التنمر البدني \\
\hline $.826^{* *}$ & التنمر اللفظي \\
\hline $.722 * *$ & الاستقو اء على الممتلكات \\
\hline
\end{tabular}

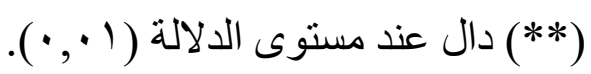

يتضح من الجدول السابق أن جميع قيم معاملات الارتباط مرتفعة ودالة إحصائًَّا عند مستوى دلالة الإنة (1 (•. ). مما يشير إلى الاتساق الداخلي المرتفع لأبعاد مقياس التنمر.

تاسعًا: نتائج الاراسة تفسيرها ومناقثتها

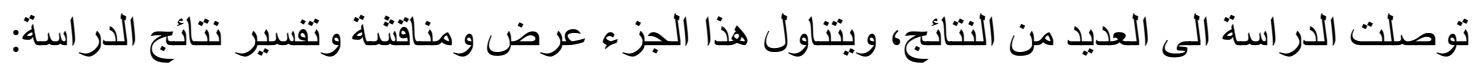




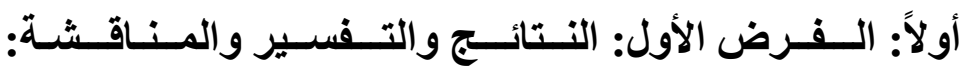

ينص الفرض الأول على أنه: "توجد علاقة ارتباطية دالة إحصائية بين درجات عينة الدراسة علي مقياسي تقدير الذات و التنمر", وللتحقق من هذا الفرض قام الباحث بحساب معامل الارتباط بين تقدير الذات و السلوك التنمري الجدول (ع ) يوضر فير ذلك

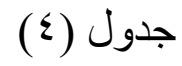

قيمة معامل الارتباط درجات عينة الدر اسة من المر اهقين على مقياس تقدير الذات و السلوك التنمري

\begin{tabular}{|c|c|c|}
\hline تقدير الذات & التنغير اتلاتلة \\
\hline
\end{tabular}

يتضح من الجدول(ع) وجود علاقة موجبة دالة إحصائَّا بين تقدير الذات والسلوك التنمري لدى الذى

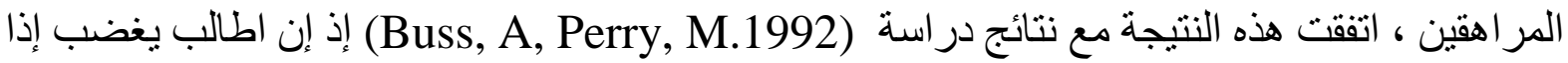

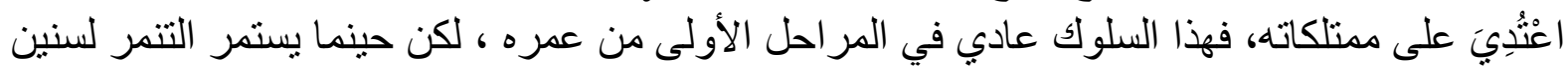

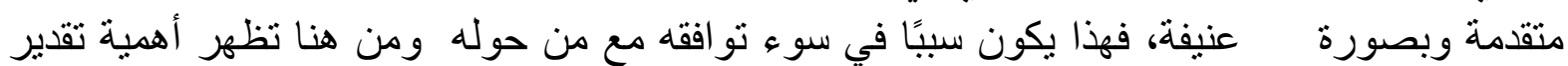
الذات في بلورة شخصية الفرد وفي تقبل الفرد لذاته ومدى مساهمته في تتظيم السلوك و وأوجه النشاط المتعددة في الحياة. ويمكن تفسير هذه النتيجة في ضوء الطابع التنمري الذي غلب على الطلاب داخل المدارس كما أن ضغوط الحياة اليومية (الأسرية، الاجتماعية، النفسية) والتي يتعرض لها الطلبة بكافة مستوياتها الدور

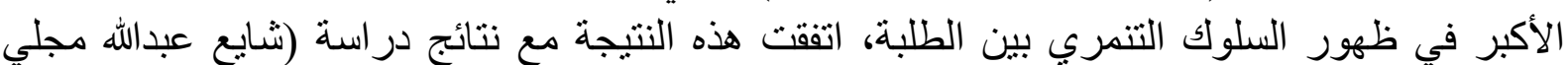

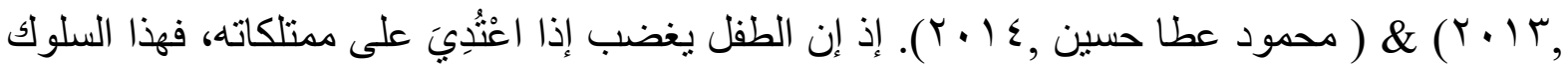

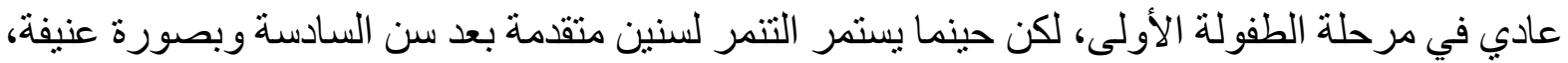

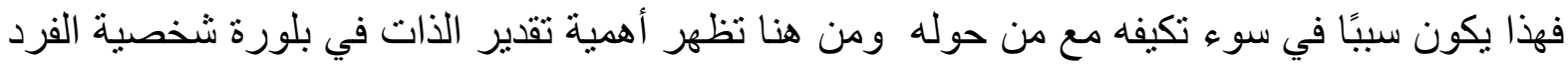
وفي تقبل الفرد لذاته ومدى مساهمته في تنظيم السلوك و وأوجه النشاط المتعددة في الحياة

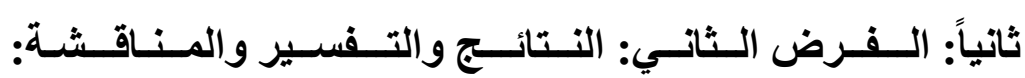

ينص الفرض الثاني على أنه::" لا توجد فروق دالة احصائيا بين درجات مجموعة الأكور ومجموعة

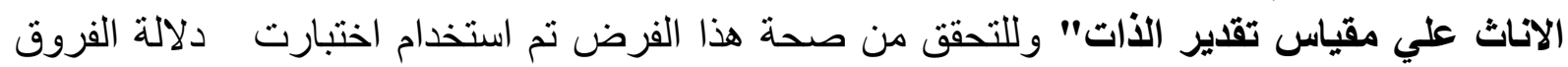
لإيجاد الفروق بين متوسط درجات كل من الذكور و الاناث في تقدير الذات وكانت النتائج كالتالي: 
جدول(0) (0) (ن)

الهتوسطات و الانحر افات المعيارية وقيم اختبار (ت)ودلالتها للفروق بين الذكور و الإناث على مقياس تقدير الذات (ت) تلات

\begin{tabular}{|c|c|c|c|c|c|c|}
\hline \multirow{2}{*}{ مستوي } & \multirow[t]{2}{*}{ قيمة (ت) } & \multicolumn{2}{|c|}{ إناث } & \multicolumn{2}{|c|}{ ذكور } & ال \\
\hline & & الانحر اف & المتوسط & الالحياري & المتوسط & \\
\hline$\cdot \wedge \varepsilon$ & $.1 \times q_{-}$ & $r . \varepsilon r$ & YA.YI & r.rq & YA.IV & تقدير الذات العائلي \\
\hline .97 & $.1 V Y_{-}$ & r.or & r7.rT & 1.90 & YT.YV & تقدير الذات الجامعي \\
\hline$\cdot .9 Y$ & $.0 \leqslant \Lambda_{-}$ & Y.OV & YI.r. & T.OT & $Y 1.1 \leq$ & تقدير الذات الرفاقي \\
\hline$\cdot r v$ & • $. \Gamma \leq \tau_{-}$ & $7 . Y Y$ & $7 . \mathrm{T}$ & $\vee . \wedge \vee$ & 10.01 & الدرجة الكلية للمقياس \\
\hline
\end{tabular}

تشير بيانات الجدول (0) إلى أنه لا توجد فروق ذات دلالة إحصائية بين متوسطات درجات الذاتكور

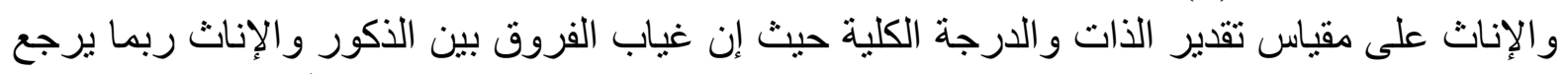

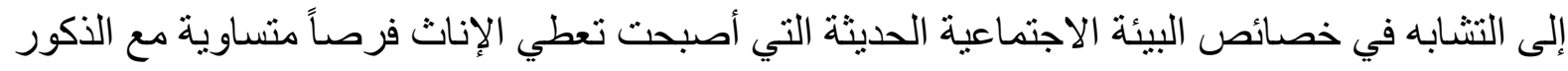

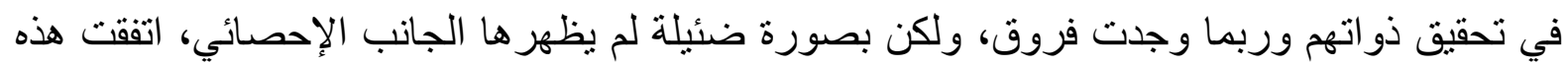

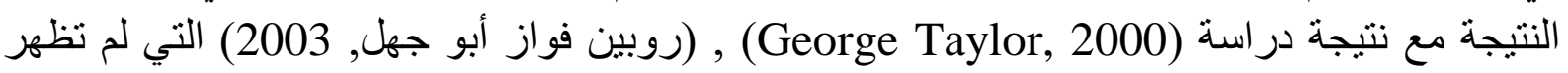
فروق ذات دلالة إحصائية بين الذكور و الإناث في تقدير الذابة الذات.

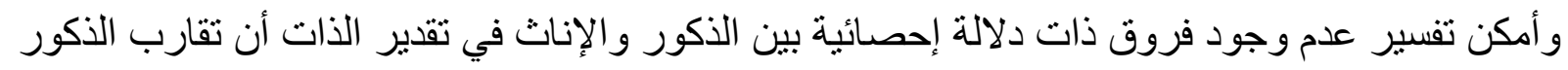

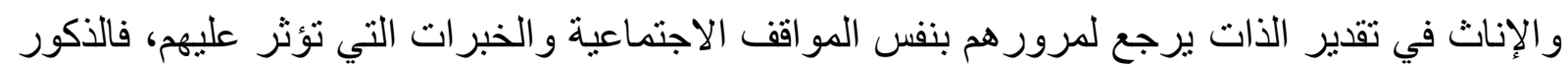

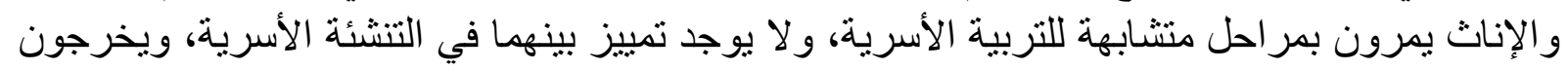

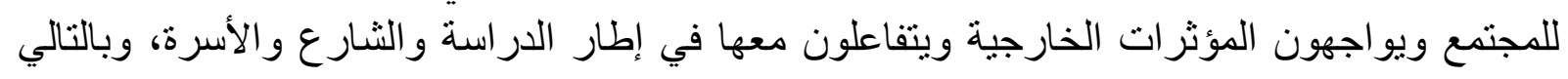
تؤثر المواقف و الخبر ات المختلفة في تقدير الذات لايهر.

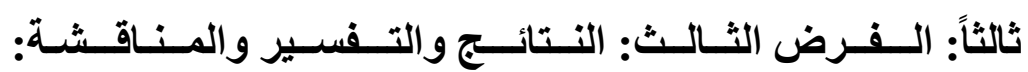

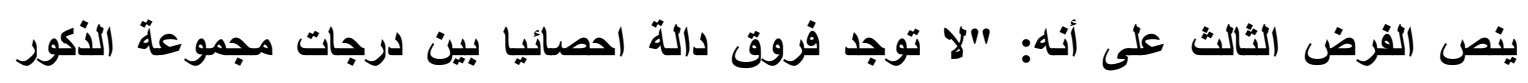

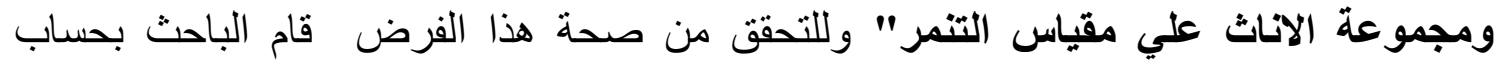

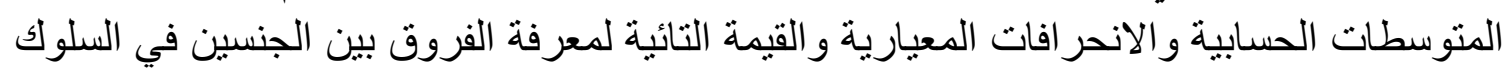

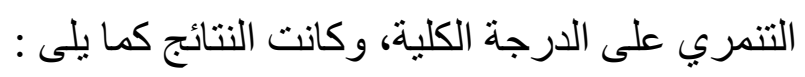

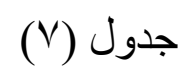

المتوسطات و الإنحر افات المعيارية وقيم اختبار (ت) ودلالتها للفروق بين الذكور و الإناث على مقياس التنمر (ت) ودلان

\begin{tabular}{|c|c|c|c|c|c|c|}
\hline مستوى الدلالة & "قيمة" & الالنحر اف & المتوسط & ن & المتغير ات & مقياس التنمر \\
\hline \multirow{2}{*}{$\because .0$} & \multirow{2}{*}{$\because V V$} & $7 . \vee 91$ & NI.rY & 0. & ذكور & \multirow{2}{*}{ الدرجة الكلية } \\
\hline & & $1.0 \wedge r$ & $1 \cdot .0$ & 0 . & إناث & \\
\hline
\end{tabular}




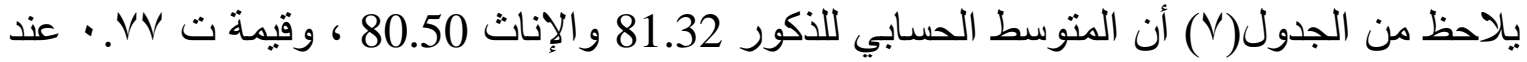

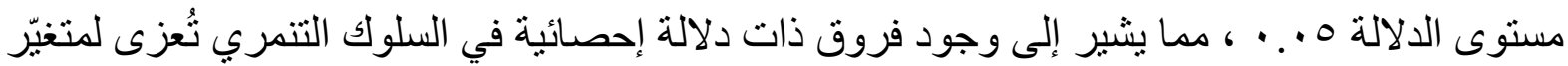

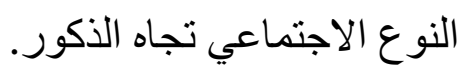

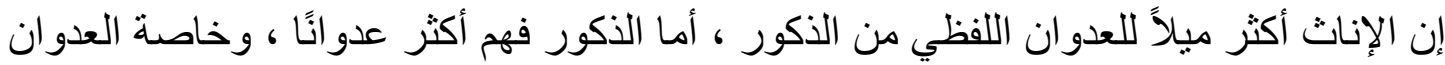

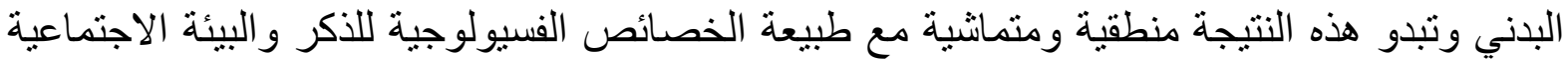

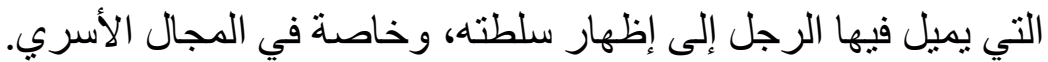

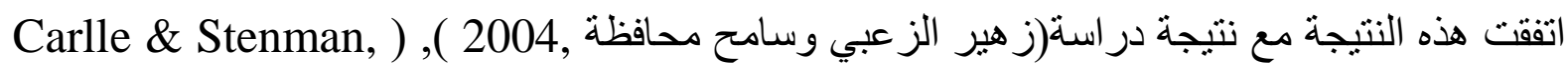

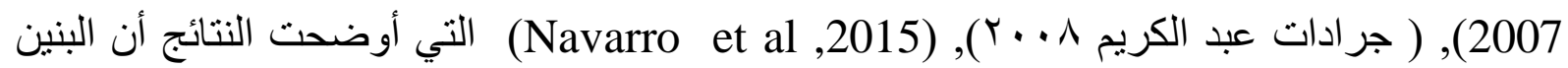

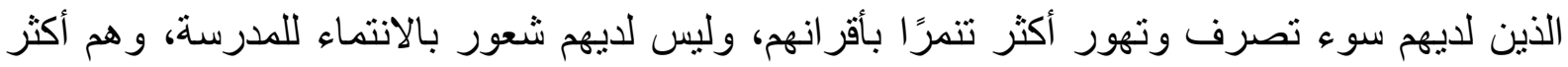

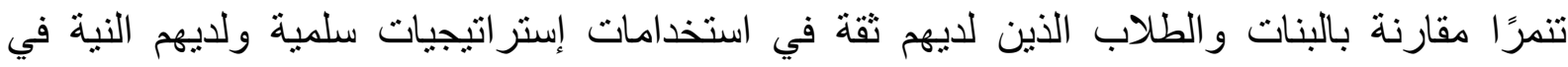

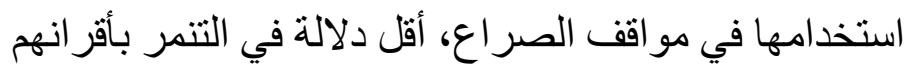

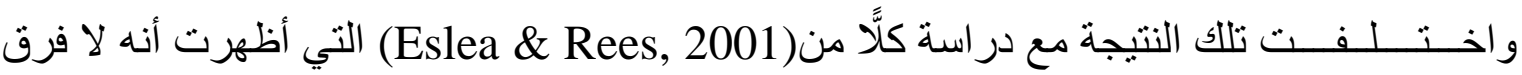

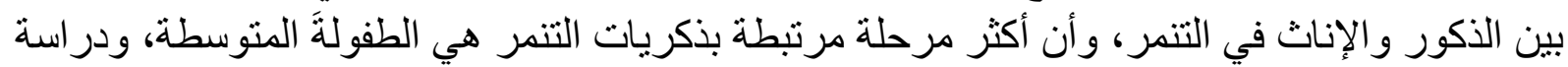

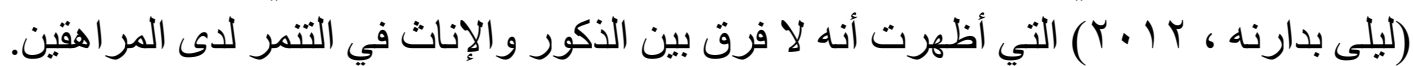

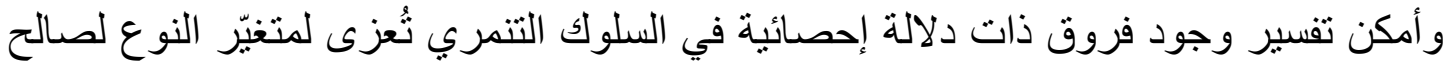

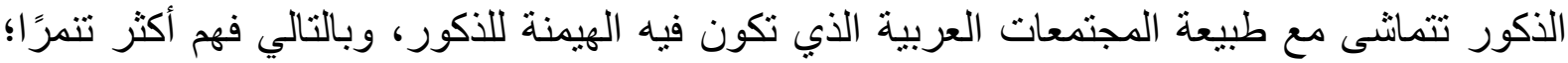

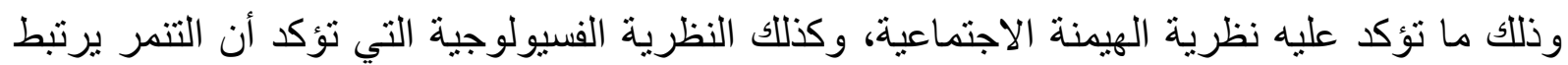

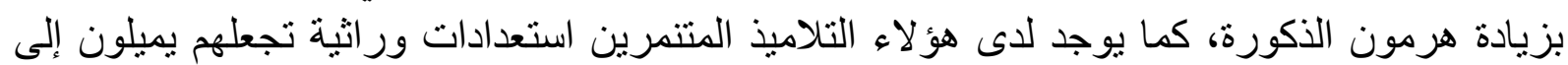
سلوك التنمر و الاعتداء على أقر انهم. عاشرًا: توصيات الاراسة

في ضوء ماتوصلت إليه الدراسة من نتائج يمكن بلورة التوصيات التالية:

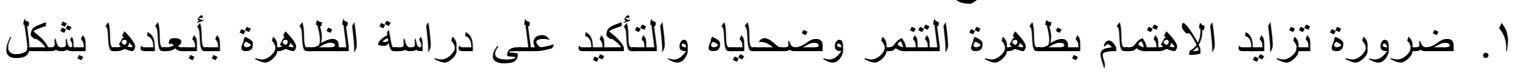
خاص في البيئة المدرسية. r. r. ضرورة العمل على توفير بيئة تعلم أمنة خالية من التنمر.

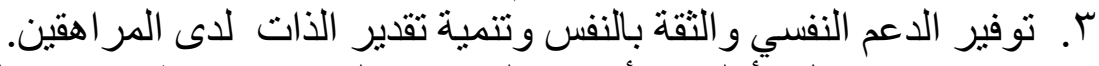

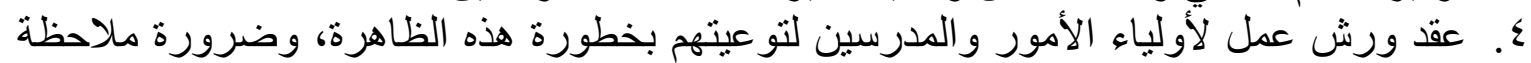

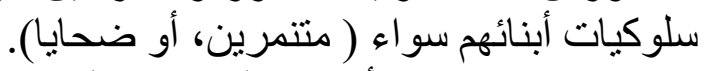

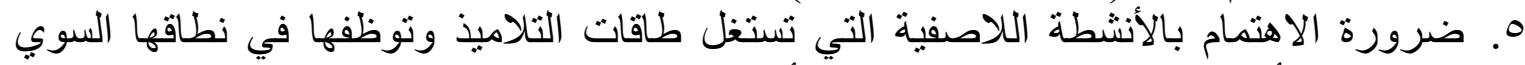

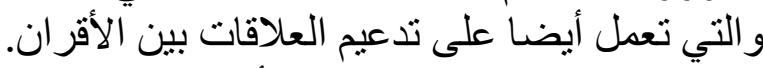

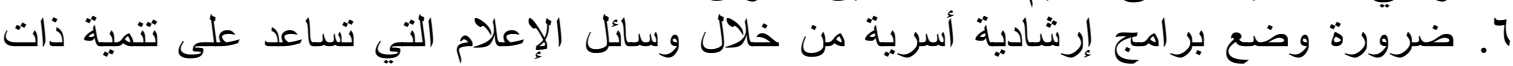

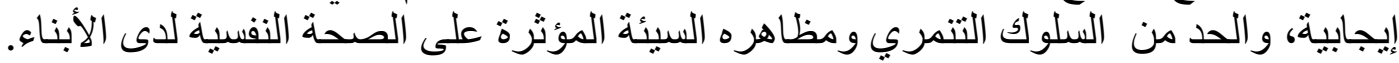

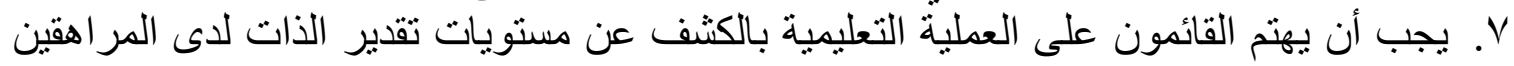

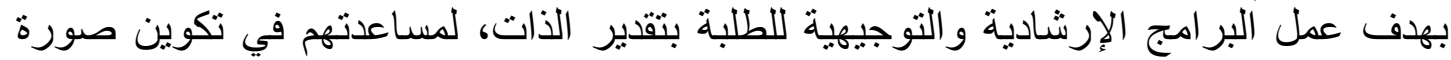

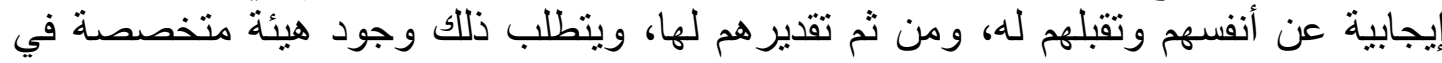
الإرشاد والتوجيه النفسي الطلابي للمر اهقين. 
في ضوء نتائج الدر اسة أمكن طر ح بعض البحوث و الدر اسات المقترحة كما يلي:

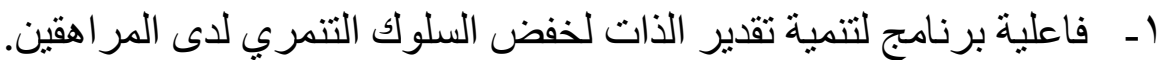

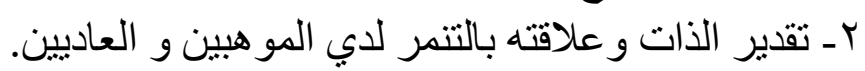

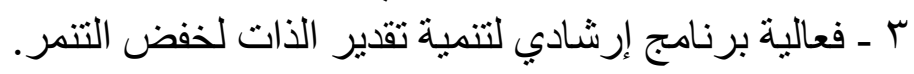

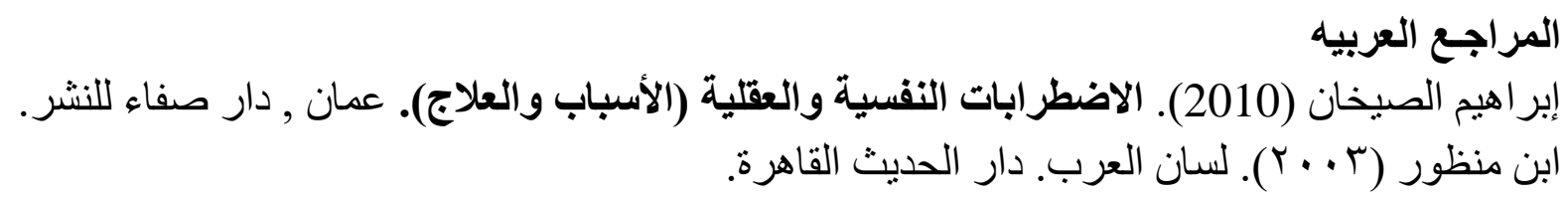

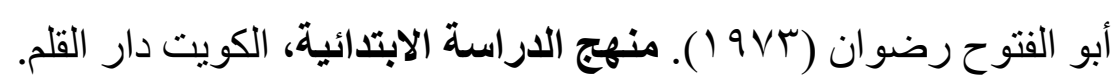
أحمد أبو زيد إبراهيم ( 1987) ـ سيكولوجية الذات والتوافق، الإسكندرية: دار المعرفة.

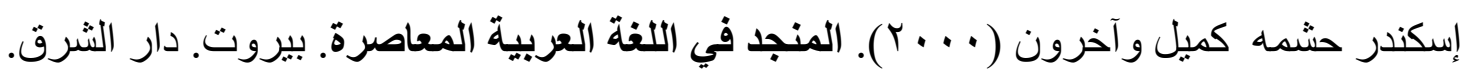

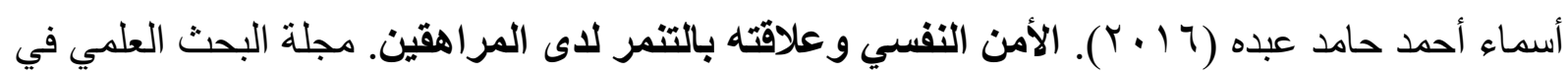

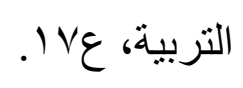

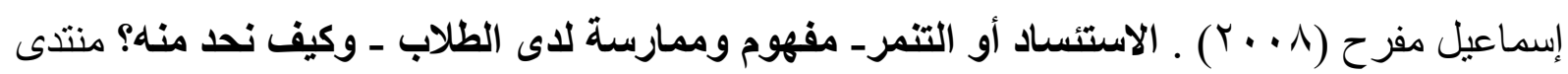

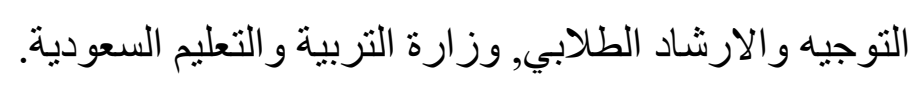

انتصار يونس(ه . . Y ). العدوان، القاهرة، دار المعارف.

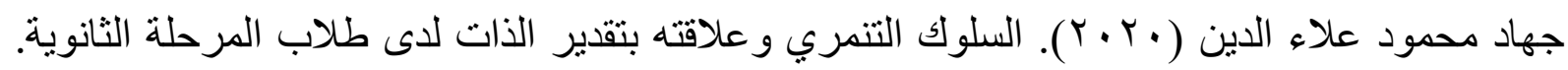
مجلة جامعة الأقصى، (سلسلة العلوم الإنسانية) ( ( ).

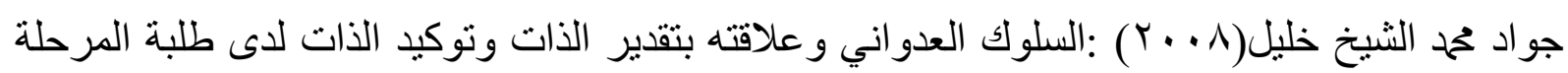
الثانوية في محافظة غزة. رسالة دكتور راه غير منشورة. جامعة الدول العربية, القاهرة. حامد عبدالسلام زهران (1974). الصحة النفسية والعلاج النفسي, القاهرة, عالم الكتب. حسين على فايد (1996 ): أبعاد السلوك العدواني لدى شباب الجامعة "دراسة مقارنة المؤتمر الدولي

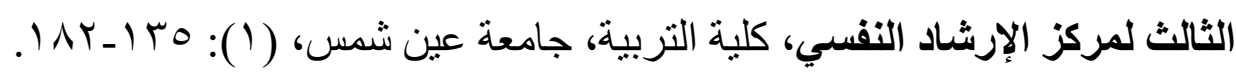
حنان أسعد خوج (1) (1) التنمر المدرسي وعلاقته بالمهار ات الاجتماعية لدى تلاميذ المرحلة الابتدائية

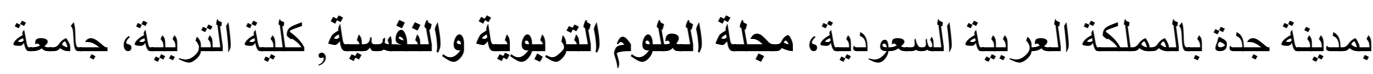

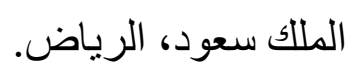
رضوان شعبان وعادل هريدي (2001) العلاقة بين المساندة الاجتماعية وكل مظاهر الاكتئاب وتقدير

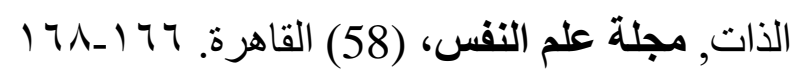


روبين فو از أبو جهل( 2003) :القلق للى طلبة كلية التربية الحكومية بغزة وعلاقته بتقدير الذات وبعض المتغير ات الأخرى،" رسالة ماجستير غير منثورة"، مودعة بجامعة القس المفتوحة :غزة.

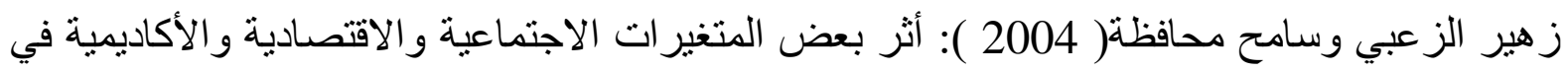
الميل نحو السلوك العدواني لاى طلبة الجامعة الهاثمية. رسالة دكتوراه غير منشورة . الجامعة الهاثمية، الأردن

سليم عوده الزبون ( 2015 ):العنف الأسري و علاقته بالوسو اس القهري لدى طلبة الجامعات الأردنية،

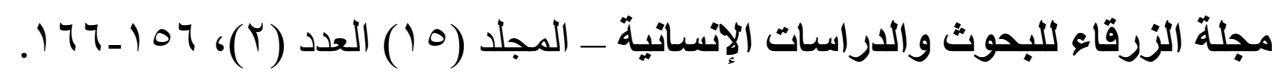

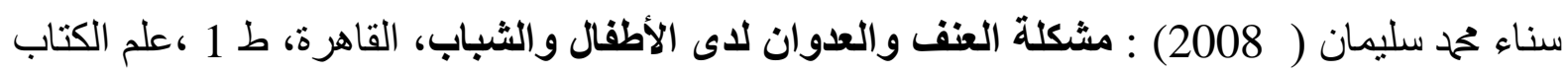
للنشر و التوزيع.

سهير كامل أحمد (2000 ):أساليب تربية الطفل(بين النظرية والتطبيق)، القاهرة : مركز الإسكندرية. السيد خيري (1970): الإحصاء في البحوث النفسية والتربوية والاجتماعية، القاهرة: دار النهضية.

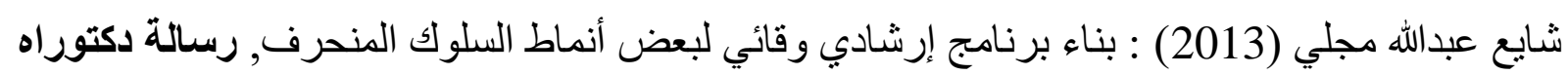
غير منشورة، كلية التربية رجامعة المستنصرية. صوفي فطيم زهير(9 (Y)). المناخ المدرسي وعلاقته بالتتمر لاى تلاميذ المرحلة الابتدائية ، رسالة

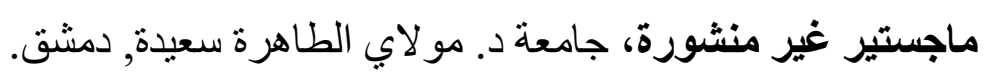

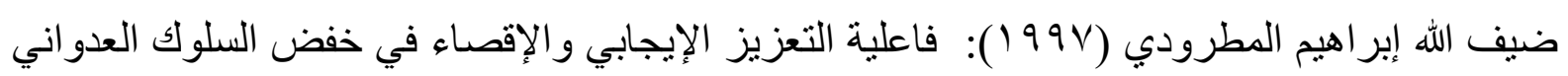

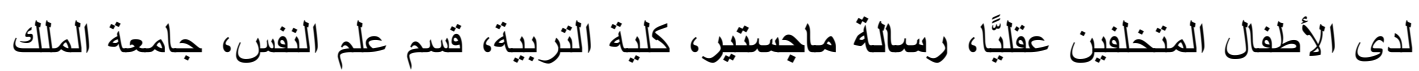

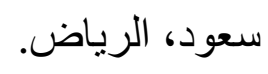

طه ربيع عدوي (ع ا ب (Y). برنامج توكيدي لتمكين ضحايا التنمر المدرسي لدى عينة من تلاميذ المرحلة

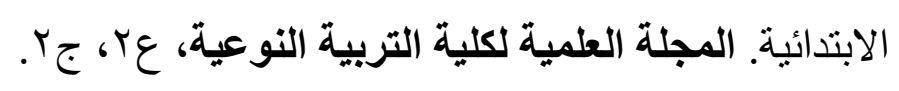

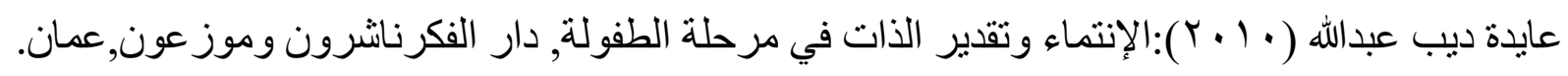

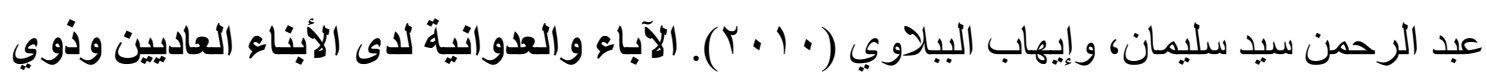
الاحتياجات الخاصة، دار الزهر اء، الرياض.

عبد الرحمن محمد (2007). دراسات في علم النفس الاجتماعي، بيروت :دار ومكتبة الهلال للطباعة الزيات و النشر.

عبد الرحمن محمد العيسوي ( 2005 ). فن القياس النفسي، دار الفكر العربي، بيروت. 
عبد ربه شعبان (• ( ( )): الخجل وعلاقته بتقدير الذات ومستوى الطموح لدى المعاقين بصريا. رسالة ماجستير غير منشورة. الجامعة الإسلامية , غزة.

عصام عبد اللطيف العقاد ( 2001 ) .سيكولوجية العدوانية وترويضها" منحنى علاجي معرفي جديد، الإندا،

$$
\text { القاهرة، دار غريب للطباعة والنشر. }
$$

عفراء بنت نايف بن عبد العزيز السديري (2000) :أثر ممارسة الأنشطة الفنية والحركية على درجة

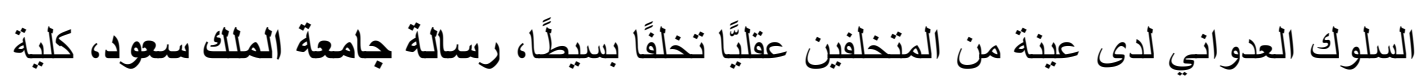

$$
\text { التربية، قسم علم النفس. }
$$

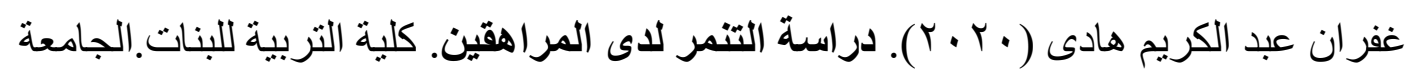
الهاثمية، الأردن.

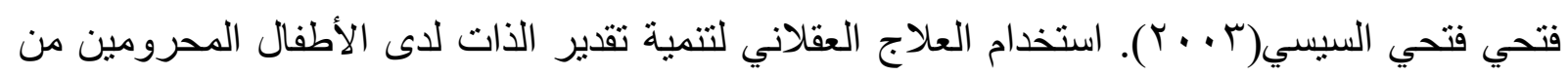
الر عاية الأسرية ,مجلة في الخدمة الإجتماعية والعلوم الإنسانية, العدده ا رالجزء الثئه الثاني.

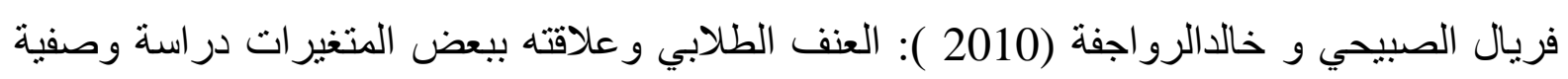

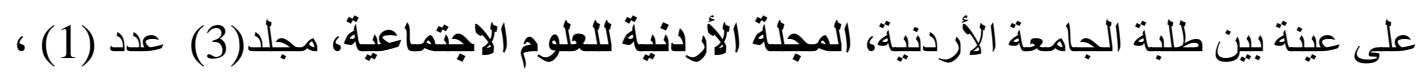
عمان .

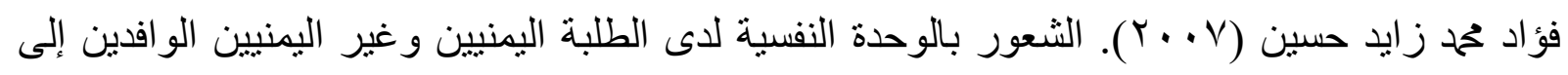

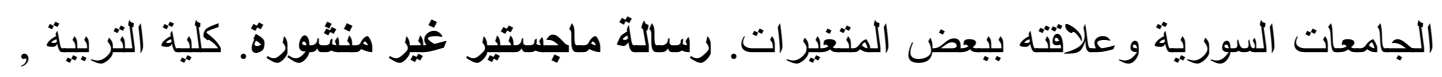

$$
\text { دمشق. }
$$

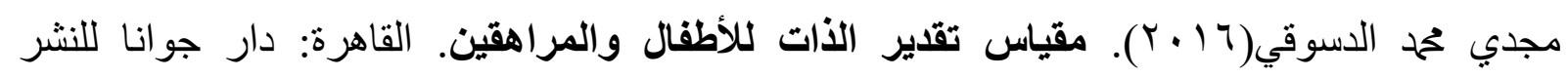

$$
\text { والتوزيع. }
$$

مجمع اللغة العربية (ء . . Y). المعجم الوسيط. طء، مكتبة الثروق الدولية. محم محمود يونس(7 1 • ب).الحالات الانفعالية المميزة للتلاميذ المتنمرين مقارنة بالتلاميذ غير المتتمرين. مجلة اتحاد الجامعات العربية للتربية وعلم النفس، ع ( (1). (1).

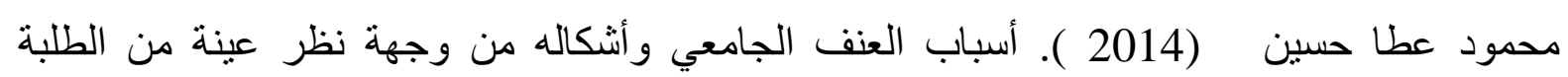

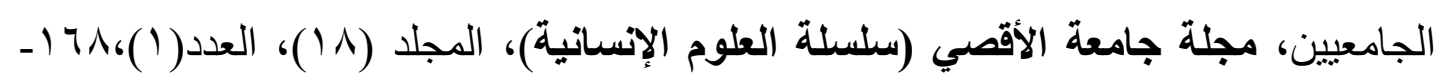
.197

مصطفى فهمي ومحمد على القطان ( 1979 ). التوافق الثخصي والاجتماعي، القاهرة، مكتبة الخانجى. 
ناجي عبد العظيم سعيد مرشد ( 2006 ). تعديل السلوك العدواني للأطفال العاديين وذوي الاحتياجات

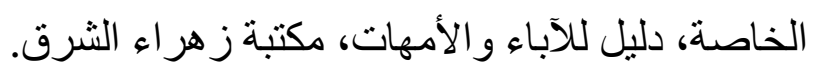

المر اجع الاجنبيه

Bryden, P. \& Fletcher, P., (2007). Personal safety practices beliefs and attitudes of female faculty and staff on a small university Comparison of males and females. College Students Journal. 41(4) retrieved November, 20, 2011. from EBSCO host master file database.

Buss, H. and Perry, K, (1995). The aggression questionnaire" of personality and social psychology, Vol. 63(3), 452-45.

Carlle, E. \& Stenman J. (2007). Demographic Differences in the Prevalence Co-Occurrence and Correlates of Adolescent Bullying at School. Journal of School Health. 77(9), 9 623-629.

Dervishi. E, Lala. M \& Ibrahimi, S.(2019). School bullying and symptoms of depression. Archives of Psychiatry and Psychotherapy, (2), 48-55. DOI: 10.12740/APP/103658.

Ebel, R.,I. (1972). Essentials of educational measurement. Englewood Cliffs, New Jersey, Prentice-Hall-2nd.

Ellis, S. (2017). Adolescents "Preception of self esteem." A Newzland Study. International. Jornal of Adolescence and Youth. 2(7), 324-335.

Eslea, M \& Rees, J. (2001). At What Age Are Children Most Likely to Be Bullied at School?. Aggressive Behavior. (27(3), 419-429.

Farmer, T. W , Petrin , R. A, Robertson, D. L, Fraser. M. W, Hall, C. M, Day, S. H \& Dadisman, K. (2010). Peer Relations of Bullies, Bully-Victims and Victims: The Two Social Worlds of Bullying in Second- Grade Classrooms. The Elementary School Journal, 110(3), 364-393.

Gilbert, A. (2000). Study Finds Bullies and victims are More alike than different graup likely to be Suffering From depression .Retrived October 5/2006 From http://www.sfgate.com

Ireland, J. \& Archer, J. (2004). Association Between Measures of Aggression and bullying Among Juvenile and Young offenders. Aggression Behavior 30 /29-42.

Juvenon, S., Graham, M. \& Shuster, R. (2003) Bullying Among Yonng adolescent . the Strory .The weak and the Troubled pediatric 112(6), 213- 229.

Martinot, D. (2002). Le Soi. Les approaches psychological. Grenoble: Press Universitaries. 
Morcillo, C. Ramos - Olazagast, A. Blanco, C. Sala, R. Canino, G. Bird , H. Duarte, CS. (2015). Socio-Cultural Context and Bulling Others in Childhood. Journal of child and family studies, 24(8):2241-2249.

Mustafa Nazia (2018). Peer Victimization, Depressive Symptoms And Academic Functioning In School Children. Pak Armed Forces , 68 (5), 1387-1392.

Sarazen J,A. (2002) . Bullies and Their Victims: Identification and Interventions. A Research paper. Univeristy of Wisconsin - Stout .

Setiowati, A.(2017). Bullying And Adjustment Problems in Islamic Elementary School. Journal Penelitian Sosial Keagamaan, 25(1), 91-108. Doi: 10.21580/ws.25.1.1386.

Studer, J. \& M ynatt, P. (2015). Bullying prevention in middle schools A collaborative approach. Middle School Journal,34(5), 25-32.

Wilcox, K., \& Stephen, A. (2013). Are close friends the enemy? Online social networks, selfesteem, and self-control. Journal of Consumer research, 40(1), 90-103. Retrieved from https://academic.oup.com

Wise, K. L., \& Bundy, K. A. (1991). Social skills training for young adolescents. Adolescence Journal, 26(101), 233. 


\title{
Self-Esteem And Its Relationship To Bullying Behavior Among Teenagersabstract
}

\begin{abstract}
This study aimed to investigate the self-esteem and its relationship to bullying behavior among teenagers. The descriptive analytical method was used in this study. A sample consisted of (100) male and female students, was chosen by the stratified random method) they completed the the self-esteem scale (by Pruce , $R$ Hare,1985) translated by Magdy Mohammed (2016) and the bullying scale (by the researcher). Data were analyzed using various statistical methods. The main results of this study were that there was a significant statistical relationship between all the dimensions of the self- esteem and the dimensions of aggressive behavior. No statistical significant differences in the self-esteem between males and females were found .There are statistical significant difference in the bullying between males and females towards males.
\end{abstract}

Keyword: Self-esteem, Bullying and Adolescents. 